\title{
Landslide Susceptibility Mapping with Deep Learning Algorithms
}

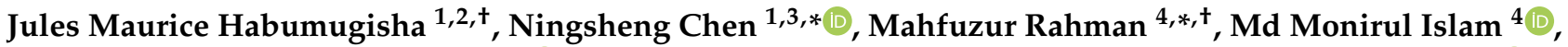 \\ Hilal Ahmad ${ }^{5}$, Ahmed Elbeltagi ${ }^{6,7}{ }^{\circ}$, Gitika Sharma ${ }^{8}$, Sharmina Naznin Liza ${ }^{9}$ and Ashraf Dewan ${ }^{10}(\mathbb{C}$
}

Citation: Habumugisha, J.M.; Chen, N.; Rahman, M.; Islam, M.M.; Ahmad, H.; Elbeltagi, A.; Sharma, G.; Liza, S.N.; Dewan, A. Landslide Susceptibility Mapping with Deep Learning Algorithms. Sustainability 2022, 14, 1734. https://doi.org/ $10.3390 /$ su14031734

Academic Editor: Christos Polykretis

Received: 7 January 2022

Accepted: 30 January 2022

Published: 2 February 2022

Publisher's Note: MDPI stays neutral with regard to jurisdictional claims in published maps and institutional affiliations.

Copyright: (C) 2022 by the authors. Licensee MDPI, Basel, Switzerland. This article is an open access article distributed under the terms and conditions of the Creative Commons Attribution (CC BY) license (https:// creativecommons.org/licenses/by/ $4.0 /)$.
1 Key Laboratory for Mountain Hazards and Earth Surface Process, Institute of Mountain Hazards and Environment, Chinese Academy of Sciences (CAS), Chengdu 610041, China; maurice@imde.ac.cn

2 University of Chinese Academy of Sciences, Beijing 100049, China

3 Academy of Plateau Science and Sustainability, Xining 810016, China

4 Department of Civil Engineering, International University of Business Agriculture and Technology (IUBAT), Dhaka 1230, Bangladesh; mmislam@iubat.edu

5 School of Civil and Resource Engineering, University of Science and Technology, Beijing 100083, China; hilal@imde.ac.cn

6 Agricultural Engineering Department, Faculty of Agriculture, Mansoura University, Mansoura 35516, Egypt; ahmedelbeltagy81@mans.edu.eg

7 College of Environmental and Resource Sciences, Zhejiang University, Hangzhou 310058, China

8 Department of Computer Science and Engineering, Thapar Institute of Engineering and Technology, Patiala 147004, Punjab, India; gsharma60_phd18@thapar.edu

9 Department of Civil Engineering, Dhaka University of Engineering \& Technology (DUET), Gazipur 1707, Bangladesh; 13106144@iubat.edu

10 School of Earth and Planetary Sciences, Curtin University, Bentley, WA 6102, Australia;

A.Dewan@curtin.edu.au

* Correspondence: chennsh@imde.ac.cn (N.C.); mfz.rahman@iubat.edu (M.R.)

+ These authors contributed equally to this work and should be considered as co-first authors.

Abstract: Among natural hazards, landslides are devastating in China. However, little is known regarding potential landslide-prone areas in Maoxian County. The goal of this study was to apply four deep learning algorithms, the convolutional neural network (CNN), deep neural network (DNN), long short-term memory (LSTM) networks, and recurrent neural network (RNN) in evaluating the possibility of landslides throughout Maoxian County, Sichuan, China. A total of 1290 landslide records was developed using historical records, field observations, and remote sensing techniques. The landslide susceptibility maps showed that most susceptible areas were along the Minjiang River and in some parts of the southeastern portion of the study area. Slope, rainfall, and distance to faults were the most influential factors affecting landslide occurrence. Results revealed that proportion of landslide susceptible areas in Maoxian County was as follows: identified landslides (13.65-23.71\%) and non-landslides (76.29-86.35\%). The resultant maps were tested against known landslide locations using the area under the curve (AUC). This study indicated that the DNN algorithm performed better than LSTM, CNN, and RNN in identifying landslides in Maoxian County, with AUC values (for prediction accuracy) of $87.30 \%, 86.50 \%, 85.60 \%$, and $82.90 \%$, respectively. The results of this study are useful for future landslide risk reduction along with devising sustainable land use planning in the study area.

Keywords: landslides; deep learning algorithm; geographic information system; Sichuan; China

\section{Introduction}

Landslides are most devastating amongst natural disasters in many parts of the world. They can result in serious problems, such as fatalities, significant injury, and widespread harm to property and infrastructures, with a cost of billions of dollars, and can trigger additional landslides [1]. According to a World Bank report, approximately 300 million 
people worldwide live in landslide-prone areas, and approximately 600 people are killed annually by landslides [2]. The economic losses from landslides are estimated to be US $\$ 20$ billion at a global scale; annually, however, countries such as the United States, Italy, India, China, and Germany experience significant losses [3].

Landslide occurrence is governed by multiple factors, i.e., heavy rainfall, earthquakes, volcanic events, elevation, slope type, vegetation cover, soil properties, and human activities, such as construction of roads, buildings, and agricultural practices [4]. However, in China, where this study was conducted (Maoxian County), landslide hazards are frequently triggered by earthquakes and heavy rainfall [5]. Maoxian County lies within the Longmenshan Belt, part of which is highly susceptible to landslides. As a result, Maoxian County experiences considerable damage. The most devastating landslide in the study area was the Xinmo landslide, that took place in the village of Xinmo, in the town of Diexi in Maoxian County, at approximately 5:39 a.m. on Saturday, 24 June 2017 [6]. That event reportedly killed 83 people and destroyed 103 housing units. A number of works related to landslide in the area were conducted by several scholars but mainly focused on geometrical features $[7,8]$, triggering mechanisms $[9,10]$, and motion processes $[6,11]$. The study area also receives greater attention due to the following reasons: (i) It is a transition region from a hilly and mountainous area around the Sichuan Basin to the Qinghai-Tibet Plateau. Thus, geomorphological features, e.g., high elevations, steep valley walls, and large slopes are widespread and believed to influence geological hazards [12]; (ii) the area is an uplift region of Chinese topography and part of active Longmen Mountain tectonic belt [13]. These tectonic movements resulted in strong earthquakes in the region (including, but not limited to, the Diexi earthquake Ms 7.5 in 1933 and the Wenchuan earthquake Ms 8.0 in 2008), which loosened surface material, damaged deep rocks and soil masses, and reduced water saturation rate [14]. These factors increased vulnerability of the study area to recurrent mountain disasters i.e., landslides and debris flows; and (iii) Maoxian has been selected by the government as one of two case study sites for undertaking geological hazard warning systems. With these motivations, it is apparent that Maoxian could be a useful site for assessing landslide susceptibility.

Nevertheless, existing studies in Maoxian have made significant contributions to the understanding of geological processes specific to landslides, but they focused on particular events. As noted above, due to its location in an active tectonic region, devastating landslides could occur in the days ahead. Moreover, the study area lacks research on landslide susceptibility. At present, no study appears to have investigated areas prone to landslides for the entire county. Therefore, to understand governing processes and support policy-makers with scientific- information, this study was conducted. The findings of the work could help save life and properties associated with landslides in Maoxian.

A geographic information system (GIS) is an effective tool for landslide assessment. GIS-based qualitative and quantitative models are commonly used to generate landslide susceptibility maps [15]. Qualitative models largely depend on experts' observations (expert knowledge-driven models) [16-19]. On the other hand, quantitative methods depend on statistical models to produce landslide propensity maps [20-22]. Machine learning algorithms (MLAs) and artificial intelligence methods have become popular for various applications in multiple fields in recent years. MLAs can be used to design self-improving models in order to obtain desired results [15,22-26]. Each of the models has its advantages and disadvantages. However, although many researchers have utilized different models to produce landslide susceptibility maps (LSMs) in different regions globally, there is little consensus about the best model to be considered in landslide susceptibility modeling. In addition, widely utilized traditional MLAs have a comparatively shallow model structure, which renders it impossible to thoroughly investigate dynamic linear and non-linear interactions between landslides and predisposing factors [27]. In recent years, deep learning algorithms have shown substantial progress, particularly in image-based analysis [28,29]. Additionally, it has a deeper algorithmic structure, and this might be useful to examine its performance in landslide susceptibility modeling. Hence, this study compares the 
performance of four deep learning algorithms (i.e., CNN, convolutional neural network; LSTM, long short-term memory; DNN, deep neural network; and RNN, recurrent neural network) by concentrating on their main distinct features. The key distinction between the algorithms proposed and the studies that have been revealed earlier is that the four deep learning algorithms are for the first-hand application for landslide susceptibility assessment. A detailed comparative analysis between multiple algorithms is required to define the problem better, assert innovative solutions, and review the effectiveness of algorithms to improve landslides prediction. Hence, this study can advance the knowledge base to better predict landslide. In addition, the main motivation to propose deep learning algorithms is that these have yielded highly accurate results in landslide susceptibility assessments in recent years. Alternatively, these algorithms determine the most appropriate mathematical transformation to use to turn the input into the output (whether the transformation is based on linear or nonlinear associations). Contrary to conventional wisdom, deep learning algorithms outperform the traditional machine learning algorithms in many instances. A deep learning approach is thus developed here to assess landslide risk in the study area.

The objectives of this study are to: (i) compare precision of different deep learning algorithms through the area under the curve (AUC) to select the best algorithm for landslide susceptibility mapping, (ii) develop a landslide susceptibility map, and (iii) identify critical conditioning factors, influencing landslide occurrences in the study area. This insight is essential to construct precise and consistent landslide susceptibility maps from which rigorous conclusions can be drawn about deep learning algorithms. The findings can be valuable to local authorities in sustainable land development. Precisely, landslides usually pose great threats to the environment and socioeconomic development. Therefore, it is crucial to evaluate areas susceptible to landslide events; this can help in the landslide disaster control and contribute to environmental sustainability and protect lives and properties. This can be achieved through appropriate planning based on valuable information obtained from landslide susceptibility study.

\section{Materials and Methods}

\subsection{Description of the Study Area}

Maoxian County is located in the northwest part of Sichuan Province, China. It lies between $31^{\circ} 24^{\prime}-32^{\circ} 17^{\prime} \mathrm{N}$ and $102^{\circ} 56^{\prime}-104^{\circ} 10^{\prime} \mathrm{E}$ (Figure 1), covers approximately $3793 \mathrm{~km}^{2}$ and is characterized by a complex geological structure (i.e., rocky hills and high mountain territories covered by thick forests and deep valleys). The elevation of Moaxian ranges from 887 to $5163 \mathrm{~m}$ above sea level (a.s.l). The difference in surface height from the bottom of the valley to the peak of the mountain can be between 1500 and $2500 \mathrm{~m}$. Approximately $1 \%$ of total area of the county is characterized by flat topography [30], whereas the rest, $99 \%$ comprises hilly and steep topography. As of 2020, the estimated population of Maoxian was 111,452 persons [12].

Maoxian County has a temperate climate with an average annual rainfall of approximately $491 \mathrm{~mm}$, and 70-90\% rain occurs during the rainy season (June to September) [31]. The climate is generally influenced by westerlies and the Tibetan Plateau monsoon, resulting in dry valleys and humid high mountains [32]. Average annual temperature of the county is $11.2{ }^{\circ} \mathrm{C}[30,33]$, and annual average relative humidity is $72 \%$ [33].

With a mean monthly temperature of $20.8^{\circ} \mathrm{C}$, July is the warmest month. January, with a mean temperature of $0.4{ }^{\circ} \mathrm{C}$, is the coldest month [33]. The main river in Maoxian is the Minjiang, which flows from north to south but crisscrosses the entire territory. It has several tributaries, including the Heishui, Chi-Bu-Su, Songping, and Tumen Rivers.

The landslide incident in the study area is attributable to the area's proximity to a seismic belt, steep terrain mantled with a layer of superficial deposits, and the recurrent long-duration rainfall. As mentioned above, Maoxian is located in the Longmen Mountain seismic belt, hence prone to landslides. Therefore, many studies have shown that landslide occurrences in Moaxian are closely related to historical earthquakes. The Diexi Ms 7.5 earthquake in 1933 had the highest seismic effect on the rock mass over the past 
100 years [11], and it is regarded as the most devastating historic incident in Maoxian because it resulted in numerous landslides that blocked rivers, such as the Mingjiang River and Songpinggou River [34]. The blockage of these rivers resulted in the formation of dammed lakes. For instance, two dammed lakes, Dahaizi and Xiaohaizi, are situated along Minjiang River, and three lakes were created along the Songpinggou River, which is a tributary of the Minjiang [35]. Figure 2 illustrates topographies of previous landslides, including the Xinmo landslide. Based on the field investigation of June 2020, the Xinmo landslide has the following three zones: source area, transport area, and deposition area (Figure 2c).

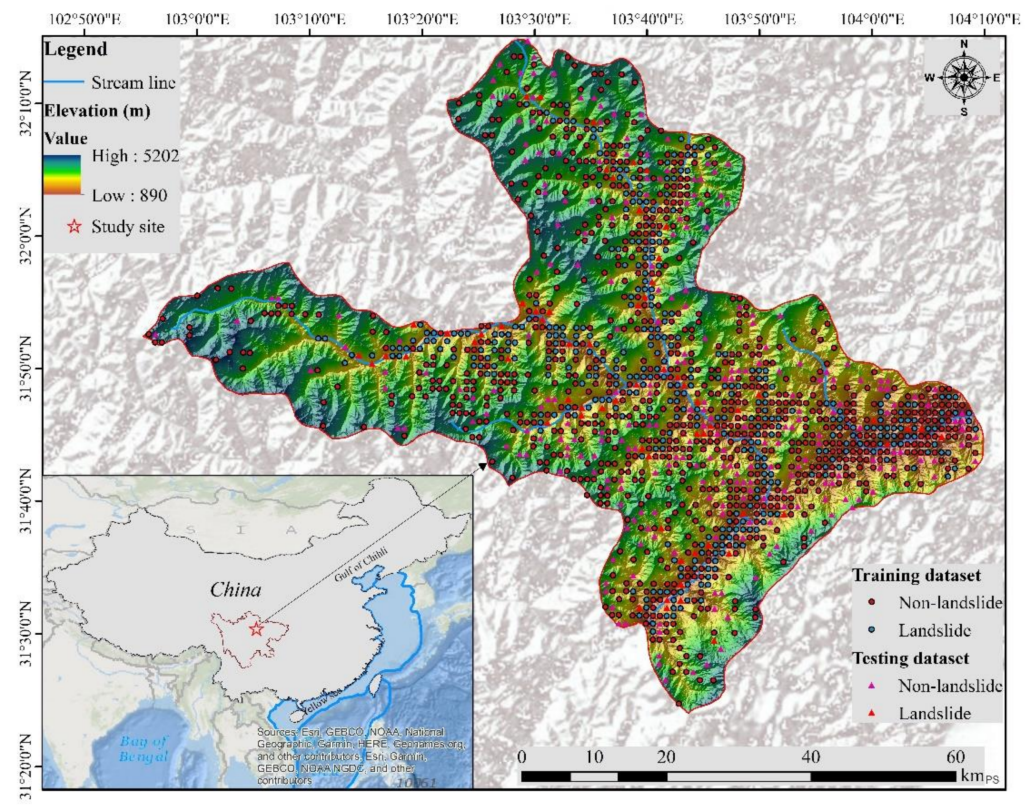

Figure 1. Location of the study area.

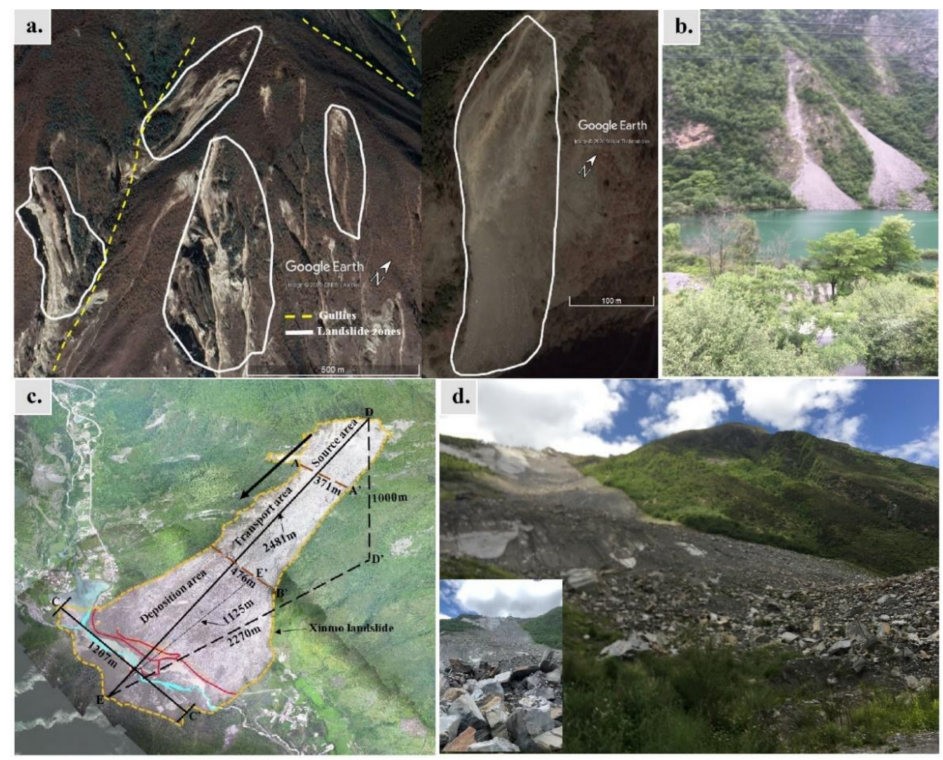

Figure 2. Landslides in Maoxian: (a) antecedent landslides (source: Google Earth); (b) some landslides in the study area (source: field visit); (c) geometric structure of the Xinmo landslide [The background image was obtained from http:/ / www.scgis.net/mxxy/ (accessed on 12 August 2020), and detail of the image is from [36]]; and (d) image of the Xinmo landslide. Photographs were taken during the field visit on 2 June 2020. 
In Maoxian, there are three main groups of active fault zones; the Longmenshan fault, trending northeast, Songpinggou fault, trending northwest, and the Minjiang fault, which trends north-south [36]. Geology of the area consists of sedimentary and metamorphic rocks of the Neoproterozoic, Mesoproterozoic, Cambrian, Ordovician, Carboniferous, Permian, Triassic, and Cretaceous eras (Table 1), and lithologies of Maoxian consist of dark-gray slate with interbeds of quartzose metamorphic sandstone and grayish-black grayish-green, and gray slate with interbeds of carbonaceous limestone and quartzose metamorphic siltstone [37].

Table 1. Geologic units and lithologies of Maoxian County [38].

\begin{tabular}{|c|c|c|c|}
\hline Eon & Era & Geological Unit & Lithological Description \\
\hline \multirow{6}{*}{ Phanerozoic } & \multirow[b]{2}{*}{ Mesozoic } & Cretaceous (K) & Clastic rock, argillaceous rock \\
\hline & & Triassic $(\mathrm{T})$ & $\begin{array}{l}\text { Gray limestone, gray and sandy mudstones, thick feldspathic } \\
\text { quartzose sandstone interlayered with shale }\end{array}$ \\
\hline & \multirow{4}{*}{ Paleozoic } & Permian $(\mathrm{P})$ & $\begin{array}{l}\text { Thick limestone intercalated with slate, carbonate-rich shale, } \\
\text { and claystone }\end{array}$ \\
\hline & & Carboniferous (C) & Epimetamorphic carbonate rock intercalated with clastic rock \\
\hline & & Ordovician $(\mathrm{O})$ & Thin-medium-thick argillaceous limestone \\
\hline & & Cambrian $(\epsilon)$ & $\begin{array}{l}\text { Black siliceous phyllite, black silicalite intercalated with } \\
\text { siliceous slate }\end{array}$ \\
\hline \multirow[t]{2}{*}{ Precambrian } & \multirow{2}{*}{ Proterozoic } & Neoproterozoic (Z) & $\begin{array}{l}\text { Volcanic and pyroclastic rock formation, tilly clastic } \\
\text { rock formation }\end{array}$ \\
\hline & & Mesoproterozoic (Y) & Clastic rock formation and carbonate rock formation \\
\hline
\end{tabular}

\subsection{Data Acquisition}

\subsubsection{Landslide Inventory Map}

To perform a landslide susceptibility assessment, we generate a landslide inventory map that can be used for reference. A landslide inventory map may also provide information necessary to evaluate types of landslides, locations, frequencies, and triggering factors [39]. Many methods, including satellite imagery, and field investigations, have been used to identify landslides to develop a landslide inventory map [40]. In this study, data on previous landslide locations used for a preparing landslide inventory map was acquired from the Sichuan Provincial Administration Office. In addition, remote sensing techniques (Google Earth Pro) and field observations were employed to compile and update landslide locations to employ for a comprehensive inventory.

In total, 1290 landslide locational points, 1248 obtained from Sichuan provincial officials, and 42 based on satellite interpretation supported by field visits, were included in the inventory data. These points were divided randomly into two groups: training points (70\%) and validation points (30\%) [41,42]. Thus, 903 training points were employed for modeling, and the rest (387) was for validation. We also collected 1290 points representing non-landslide areas, which were then merged with the landslide points to validate the models. More specifically, the non-landslide points were compiled using remote sensing technique (Google Earth Pro) and field observations. First of all, landslide points acquired from the Sichuan Provincial Administration Office were imported into Google Earth Pro in order to easily find non-landslide occurrence locations and to avoid overlapping between landslide and non-landslide points. After this, non-landslide points were spatially and temporally compiled with the use of Google Earth Pro, and later, the data were extracted and imported to ArcGIS for further assessment.

\subsubsection{Landslide Predisposing Factors}

In this study, 13 different predisposing factors were considered and used to assess landslide susceptibility. The factors were chosen based on field visits and literature. Input 
data for these factors were obtained from different sources and subsequently processed and analyzed. All 13 factors were then transformed into raster format and harmonized to $30 \times 30 \mathrm{~m}$ cell size. The maps of factors, such as slope angle, elevation, aspect, topographic wetness index (TWI), plan curvature, and stream power index (SPI), were determined using a Digital Elevation Model (DEM), acquired from Earth Explorer (https: / / earthexplorer. usgs.gov/ accessed on 12 August 2020). The DEM has a resolution of $30 \mathrm{~m}$. Details of influencing factors are described in Table 2.

Table 2. Description of data used in this study.

\begin{tabular}{|c|c|c|c|}
\hline Factor & Classes & Source of Data & Reference \\
\hline Slope angle (degrees) & $\begin{array}{l}\text { (i) 0-15, (ii) 15-30, (iii) 30-45, (iv) 45-60, } \\
\text { and (v) > } 60 \\
\text { Method: manual classification }\end{array}$ & Extracted from DEM: $30 \mathrm{~m} \times 30 \mathrm{~m}$ & $\begin{array}{l}\text { Moharrami et al. [17], } \\
\text { Tang et al. [43] }\end{array}$ \\
\hline Elevation (m) & $\begin{array}{l}\text { (i) }<1750 \text {, (ii) 1750-2600, (iii) 2600-3450, } \\
\text { (iv) 3450-4300, and (v) >4300 } \\
\text { Method: manual classification }\end{array}$ & $\begin{array}{l}\text { https:/ / earthexplorer.usgs.gov/ } \\
\text { (accessed on } 12 \text { August 2020) } \\
\text { DEM: } 30 \mathrm{~m} \times 30 \mathrm{~m}\end{array}$ & Intarawichian and Dasananda [44] \\
\hline Aspect & $\begin{array}{l}\text { (i) Flat, (ii) North, (iii) Northeast, (iv) East, } \\
\text { (v) Southeast, (vi) South, (vii) Southwest, } \\
\text { (viii)West, and (ix) Northwest }\end{array}$ & Extracted from DEM: $30 \mathrm{~m} \times 30 \mathrm{~m}$ & $\begin{array}{l}\text { Vijith and Madhu [45], } \\
\text { Kayastha [46] }\end{array}$ \\
\hline Plan curvature & $\begin{array}{l}\text { (i) Concave, (ii) Flat, and (iii) Convex } \\
\text { Method: manual classification }\end{array}$ & Extracted from DEM: $30 \mathrm{~m} \times 30 \mathrm{~m}$ & $\begin{array}{l}\text { Nefeslioglu et al. [47], } \\
\text { Yilmaz et al. [48] }\end{array}$ \\
\hline SPI & $\begin{array}{l}\text { (i) } 0-5 \text {, (ii) } 5-10 \text {, (iii) } 10-15 \text {, (iv) } 15-20 \text {, } \\
\text { and (v) > } 20 \\
\text { Method: manual classification }\end{array}$ & $\begin{array}{l}\text { Equation (1) } \\
\text { Source from DEM: } 30 \mathrm{~m} \times 30 \mathrm{~m}\end{array}$ & Mind'je et al. [42] \\
\hline TWI & $\begin{array}{l}\text { (i) }<4 \text {, (ii) 4-6, (iii) 6-8, (iv) 8-10, and (v) }>10 \\
\text { Method: manual classification }\end{array}$ & $\begin{array}{l}\text { Equation (2) } \\
\text { Source from DEM: } 30 \mathrm{~m} \times 30 \mathrm{~m}\end{array}$ & Sørensen et al. [49] \\
\hline $\begin{array}{l}\text { Distance } \\
\text { to roads }(\mathrm{m})\end{array}$ & $\begin{array}{l}\text { (i) 0-1000, (ii) } 1000-2000 \text {, (iii) 2000-3000, } \\
\text { (iv) 3000-4000, (v) 4000-6000, (vi) 6000-8000, } \\
\text { and (vii) > } 8000 \\
\text { Method: manual classification }\end{array}$ & Extracted from Google earth & Acharya and Lee [50] \\
\hline $\begin{array}{l}\text { Distance } \\
\text { to rivers }(\mathrm{m})\end{array}$ & $\begin{array}{l}\text { (i) 0-1000, (ii) } 1000-2000 \text {, (iii) 2000-3000, } \\
\text { (iv) 3000-4000, (v) 4000-6000, (vi) 6000-8000, } \\
\text { and (vii) > } 8000 \\
\text { Method: manual classification }\end{array}$ & Extracted from Google earth & Myronidis et al. [51] \\
\hline $\begin{array}{l}\text { Distance } \\
\text { to faults (m) }\end{array}$ & $\begin{array}{l}\text { (i) 0-2000, (ii) 2000-4000, (iii) 4000-6000, } \\
\text { (iv) 6000-8000, and (v) >8000 } \\
\text { Method: manual classification }\end{array}$ & $\begin{array}{l}\text { Digitizing a geological map: } \\
\text { Scale-1:100,000 }\end{array}$ & Fan et al. [10], Meng et al. [52] \\
\hline $\begin{array}{l}\text { Normalized Difference } \\
\text { Vegetation Index (NDVI) }\end{array}$ & $\begin{array}{l}\text { (i) }-0.20-0.27 \text {, (ii) } 0.27-0.44 \text {, (iii) } 0.44-0.59 \text {, } \\
\text { (iv) } 0.59-0.70 \text {, and (v) } 0.70-0.91 \\
\text { Method: manual classification }\end{array}$ & $\begin{array}{l}\text { https://ladsweb.modaps.eosdis. } \\
\text { nasa.gov/ (accessed on } \\
12 \text { August 2020) }\end{array}$ & Mind'je et al. [42] \\
\hline $\begin{array}{l}\text { Annual mean } \\
\text { rainfall }(\mathrm{mm} / \mathrm{y})\end{array}$ & $\begin{array}{l}\text { (i) }<700 \text {, (ii) } 700-750 \text {, (iii) } 750-800, \\
\text { (iv) } 800-850 \text {, and (v) }>850 \\
\text { Method: manual classification }\end{array}$ & $\begin{array}{l}\text { chg.geog.ucsb.edu/data/chirps: } \\
\text { (accessed on } 12 \text { August 2020) }\end{array}$ & $\begin{array}{l}\text { Nahayo et al. [4], } \\
\text { Mind'je et al. [42] }\end{array}$ \\
\hline Geology & $\begin{array}{l}\text { (i) Triassic, (ii) Mesoproterozoic, } \\
\text { (iii) Permian, (iv) Cretaceous, } \\
\text { (v) Carboniferous, (vi) Ordovician, } \\
\text { (vii) Cambrian, and (viii) Neoproterozoic } \\
\text { Method: manual classification }\end{array}$ & $\begin{array}{l}\text { Digitizing a geological map: } \\
\text { Scale-1:100,000 }\end{array}$ & Meng et al. [52] \\
\hline Land Cover (LC) & $\begin{array}{l}\text { (i) Built area, (ii) Cropland, (iii) Grassland, } \\
\text { (iv) Shrubland, (v) Snow and ice, (vi) Tree } \\
\text { cover, and (vii) Water bodies } \\
\text { Method: manual classification }\end{array}$ & $\begin{array}{l}\text { https:/ / earthexplorer.usgs.gov / } \\
\text { (accessed on } 12 \text { August 2020) }\end{array}$ & $\begin{array}{l}\text { Vijith and Madhu [45], } \\
\text { Mind'je et al. [42] }\end{array}$ \\
\hline
\end{tabular}

All 13 landslide predisposing factors are briefly described below:

The slope angle expresses a change in elevation over distance. Steeper slopes are potentially prone to failure [17]. Thus, slope angle is deemed an important factor in landslide susceptibility modeling. This factor was manually divided into five different classes (Figure 3a) [43]. Variability in climate and weather conditions at different elevations can cause changes in vegetation and soil [17]. Therefore, elevation factor was taken into 
consideration due to its influence on topographic characteristics and vegetation distribution. It was also classified into five categories (Figure 3b) [44].
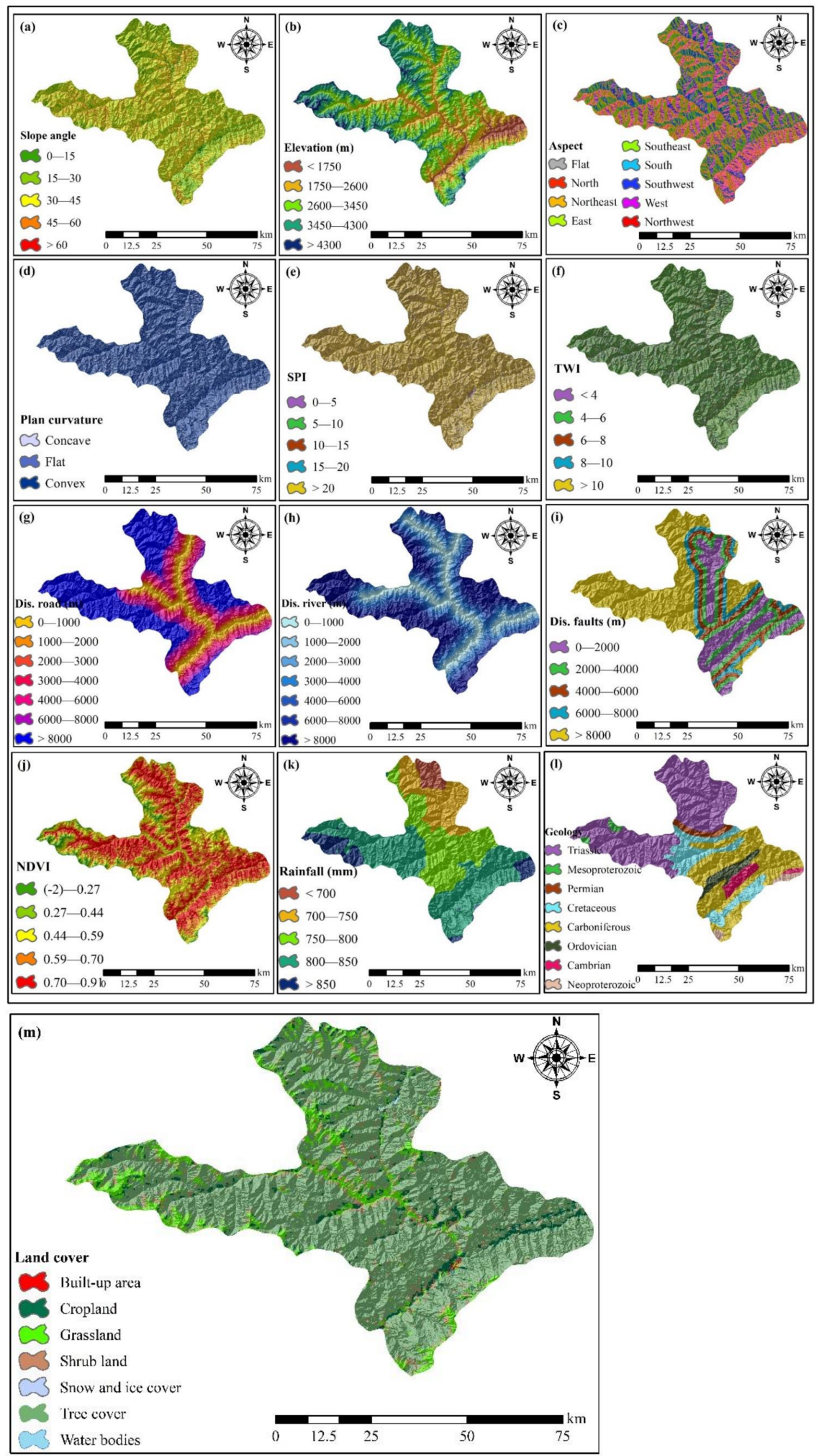

Figure 3. Landslide predisposing factors used in this study area: (a) slope angle $\left[{ }^{\circ}\right]$, (b) elevation [m], (c) aspect, (d) plan curvature, (e) SPI, (f) TWI, (g) distance to roads [m], (h) distance to rivers [m], (i) distance to faults [m], (j) NDVI, (k) average annual rainfall [mm/year], (l) geology, and (m) land cover (LC). 
Aspect is also one of the most significant factors for landslide susceptibility. It indicates the direction in which a slope faces [53] and controls the amount of water on hillsides, which can cause slope instability [43]. In the current study, aspect was classified into nine classes based on the manual classification (Figure 3c) [45,46]. Plan curvature is a measure of the concavity or convexity of a slope. It is related to landslide events because it controls the direction (convergence or divergence) of water during downhill flow [47,48]. In this study, based on the manual classification method, plan curvature was divided into three classes (Figure 3d). The stream power index (SPI) is one of the significant factors for landslide occurrence in the study area [43]. It is a hydrological factor that can influence the distribution of landslides in a region. The SPI was used to measure the erosive force of the streams or catchments [42]. Based on the DEM, the SPI was derived using Equation (1):

$$
\mathrm{SPI}=\mathrm{A}_{\mathrm{S}} \times \tan \beta,
$$

where, $A_{S}$ is defined as the specific catchment area $\left(\mathrm{m}^{2} / \mathrm{m}\right)$ and $\tan \beta$ is the tangent of the slope. We divided the SPI map into five classes using the manual classification method (Figure 3e).

The topographic wetness index (TWI) is a steady-state wetness index that is used to study the effects on hydrological processes [49]. In this study, the TWI was used to quantify topography control of hydrological processes related to landslide occurrence. It was calculated based on Equation (2):

$$
\mathrm{TWI}=\ln \left(\frac{a}{\tan b}\right)
$$

where, ' $a$ ' is the local upslope area draining through a certain point per unit contour length and ' $\tan b$ ' is the local slope in radians. The TWI map was classified into five groups (Figure 3f). Among the factors contributing to the landslide occurrence in the study area, distance to roads was considered to be important as the slope cut-off for road construction in mountainous areas causes slope instability, which can lead to landslide incidence. The distance to roads was generated by computing the Euclidean distance [42] and then dividing it into seven classes (Figure 3g). Distance to rivers was computed using the Euclidean distance [4] and then classified into seven classes (Figure 3h). Active faults can be considered to be a factor in landslide events because the strength of rock is lower along faults, which can increase the likelihood of slope failure. We generated faults by digitizing a 1:100,000 scale geological map [10,52] and then produced the distance to faults map using ArcGIS software with the aid of a Euclidean distance tool [42]. Subsequently, we grouped distances into five classes using the manual classification method (Figure 3i).

The normalized difference vegetation index (NDVI) is a measure of greenness and thus biomass. NDVI values range from -1 to 1 , which denote low to high vegetation cover in an image, respectively. Alteration in vegetated areas may lead to slope failures [54]. The NDVI data (from May to September 2019) were extracted on 25 May 2020, from the Moderate Resolution Imaging Spectroradiometer (MODIS, $250 \mathrm{~m}$ resolution) dataset available at https: / ladsweb.modaps.eosdis.nasa.gov / (accessed on 12 August 2020). It was calculated in the study area using the near-infrared and red bands (Equation (3)). Thus, a map of NDVI (Figure 3j) was derived in ArcGIS software (version 10.5: ESRI, Redlands, CA, USA).

$$
\mathrm{NDVI}=\frac{\mathrm{NIR}-\text { Red }}{\mathrm{NIR}+\text { Red }}=\frac{\text { Band } 4-\text { Band } 3}{\text { Band } 4+\text { Band } 3}
$$

Rainfall is one of the major triggering factors of landslide hazards. It increases pore water pressure and soil moisture content, which reduces soil cohesion, and thus, leads to landslide events [55]. Therefore, rainfall was also considered as a predisposing factor for landslide occurrence. However, because of the lack of rain-gauge station data in the study area, we employed onsite station data obtained from the Climate Hazards Group Infrared Precipitation (CHIRPS), which provided long-term mean annual rainfall (mm) for 
the 18-year period ranging from 2000 to 2018. After this, a rainfall map was prepared using the kriging interpolation method in ArcGIS [4,42]. The rainfall map was divided into five classes (Figure 3k). Geology is used in landslide susceptibility evaluation because different geological units (rock strata) have different susceptibility levels [17,56]. A geological map was generated by digitizing the available 1:100,000-scale geological map [52], and the strata were classified into eight geological units (Figure 31). Because of its spatial effect on the predisposition to landslide occurrence, land cover (LC) (Figure 3m) was also considered as one of the key factors influencing landslide susceptibility in Maoxian County. The LC map was produced from multispectral Landsat-8 Operational Land Imager (OLI) images for 14 April 2019, through the USGS Earth Explorer (https:/ / earthexplorer.usgs.gov/ (accessed on 12 August 2020) extracted on 23 May 2020. The map was produced based on the supervised maximum classification method, and it was classified into seven classes (Figure 3m): built-up area, cropland, grassland, shrub land, snow and ice cover, tree cover, and waterbodies.

\subsection{Multicollinearity Analysis}

Multicollinearity analysis can facilitate selecting suitable landslide predisposing factors. In this study, multicollinearity among the 13 selected factors was tested based on training data using the tolerance (TOL) and variance inflation factor (VIF) [42]. A VIF value $\geq 5$ and a TOL value $<0.1$ shows a multicollinearity problem and should exclude during [57].

\subsection{Feature Selection}

To improve the performance of the proposed algorithms, we considered Pearson's correlations to check appropriate attributes among independent variables. Attributes with a strong correlation coefficient are deemed redundant [58]. Pearson's correlation coefficient $\leq 0.70$ was considered as the threshold for appropriate features [59].

\subsection{Correlation between Landslides Occurrence and Predisposing Factors}

To evaluate spatial association between occurrence of landslide and predisposing factors, the frequency ratio (FR) model was used. An advantage of FR model is that spatial correlation between landslide occurrence and its factors per class can be revealed under the principle of basic data collection to classify susceptibility of landslides [42]. The FR model defines ratio of the likelihood of occurrence to the likelihood of non-occurrence in a given situation. If FR is $>1$, correlation between a landslide and the factor's range is high. On the contrary, if FR is $<1$, correlation is low. Thus, as the value of FR becomes higher, the likelihood of occurrence becomes larger and vice versa. In this study, FR was calculated using Equation (4) [42]:

$$
F R=\frac{\frac{W_{p i x}\left(L X_{i}\right)}{\sum_{i=1}^{m} L X_{i}}}{\frac{W_{p i x}\left(X_{j}\right)}{\sum_{j=1}^{m} W_{p i x}\left(X_{j}\right)}}=\frac{\% N_{i}}{\% M_{j}}
$$

where, $W_{\text {pix }}\left(L X_{i}\right)$ is the number of pixels with landslides within class $i$ of factor variable $X, W_{\text {pix }}\left(X_{j}\right)$ is the number of pixels within factor variable $X_{j}, m$ is the number of classes in the parameter variable $X_{i}$, and $n$ is the number of factors in the study area. $N_{i}$ denotes the number of landslides in a factor class as a percentage of all landslides, and $M_{j}$ indicates the class area as a percentage of the entire map.

\subsection{Spatial Modeling}

\subsubsection{Convolutional Neural Network (CNN)}

$\mathrm{CNN}$ is one of the most influential and significant algorithms in deep learning with multiple network architectures, i.e., 1D, 2D, and 3D-CNN [60]. In this study, 1D-CNN architectures, consisting of one convolution layer, one pooling layer (maximum), one flattening layer, and two fully connected dense layers [61], were used. The dropout layer 
was also connected to avoid overfitting. The random search method of the Keras tuner library was used to select the number of filters, kernel size, activation function, number of neurons in fully connected layers [62]. The hyper-parameters were used for random search for number of convolution filters, kernel size, activation function, learning rate, and number of neurons are as follows: $(32,48,64,80,96,112,128),(2,4,6,8),(\operatorname{ReLU}, \mathrm{eLU}),\left(1 \times 10^{2}\right.$, $\left.1 \times 10^{3}\right)$, and $(32,48,64,80,96,112,128)$, respectively. The dense layer used 'Sigmoid' as an activation function, and the 'Adam' optimization algorithm was used to train the algorithm [62]. For details regarding CNN, readers refer to the works of Matsugu et al. [63], Simard et al. [64], Cecotti [65], and Rohit and Chakravarthy [66].

\subsubsection{Deep Neural Network (DNN)}

DNN is a widely used method in assessing various natural hazards [67]. In this study, the algorithm consists of five fully connected layers and dropout layers. The hyperparameters used for the random search method for the number of neurons in fully connected layers and dropout rate are as follows: $(32,48,64,80,96,112,128)$ and $(0.01,0.02)$, respectively. The layer used the 'Sigmoid' function as an activation function [68]. The 'Adam' optimization algorithm was used to train the algorithm [68]. Further details of DNN can be found in Cireşan et al. [69], Yu et al. [70], Kang et al. [71], and Sharma et al. [72].

\subsubsection{Long Short-Term Memory Networks (LSTM)}

LSTM algorithm has a significant predictive ability [73]. The bi-directional LSTM was used in this study using the Keras library. The architecture of LSTM here consists of one bi-directional layer, a dropout layer, followed by two fully coupled layers. The hyper-parameters used for random search method for number of units, activation function, dropout rate, and number of neurons in fully connected layers are as follows: $(32,48,64$, 80, 96, 112, 128), (ReLU, eLU), (0.01, 0.02), and (32, 48, 64, 80, 96, 112, 128), respectively. The dense layer used 'Sigmoid' as an activation function [68]. The 'Adam' optimization algorithm was used to train the LSTM algorithm [68]. Further details of LSTM are discussed in Portegys [74], Wöllmer et al. [75], and Rivest et al. [76].

\subsubsection{Recurrent Neural Network (RNN)}

As a deep learning algorithm, the RNN has succeeded greatly in temporal data processing [77,78]. In this study, RNN was implemented using the simple RNN layer of the Keras library. The architecture of it consists of one simple RNN layer, the dropout layer, followed by two fully connected layers. The hyper-parameters used for random search method for number of units, activation function, dropout rate, and number of neurons in fully connected layers are as follows: $(32,48,64,80,96,112,128)$, (ReLU, eLU), (0.01, 0.02), and $(32,48,64,80,96,112,128)$, respectively. The dense layer used 'Sigmoid' as an activation function, and the 'Adam' optimization algorithm was used to train the RNN algorithm [79]. Further details on RNN are available in Chang et al. [80].

\subsection{Model Validation}

In this study, derived LSMs were validated using landslide locational points. The AUC approach was adopted to evaluate the performance of the four algorithms used. An AUC graph of sensitivity and 1-specificity was prepared [21]. We further calculated the performance matrices, i.e., recall, F1-score, and log-loss, to evaluate prediction accuracy of deep learning algorithms [81].

\section{Results and Discussion}

\subsection{Multicollinearity Assessment}

Multicollinearity among 13 landslide influential factors (Figure 4) was tested using TOL and VIF. For all of these factors, results showed that VIF values are less than 5, and TOL values are higher than 0.1 , which is in accordance with the work of O'Brien [57]. The maximum VIF and minimum TOL values were 4.128 and 0.984 , respectively. Hence, our 
results are free from multicollinearity. Therefore, all of the factors were considered in the feature selection process.

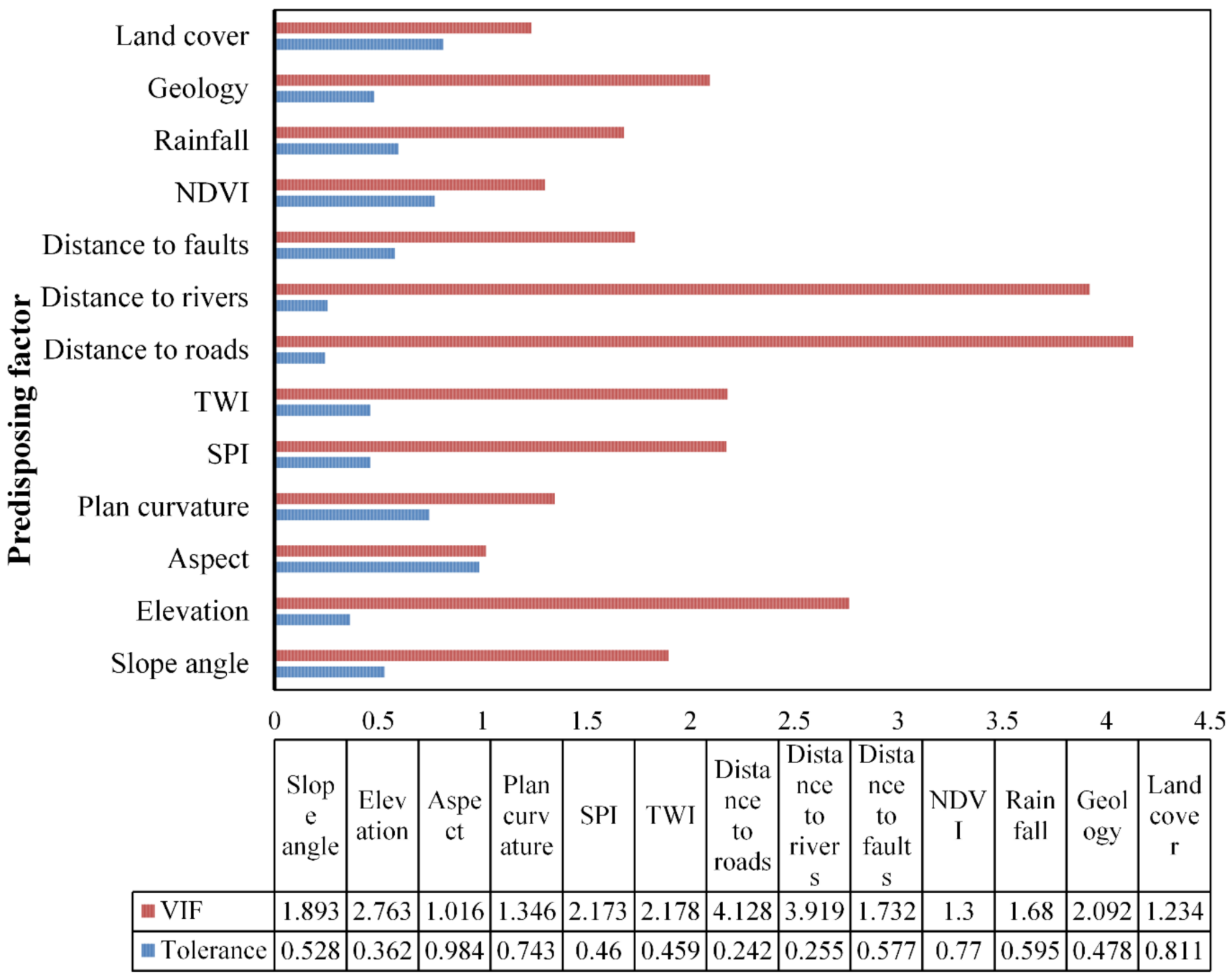

Figure 4. Multicollinearity indices for landslide predisposing factors.

\subsection{Pearson Correlation Assessment}

Results of the feature selection analysis indicate that among 13 factors, distance to rivers ( $\mathrm{Ri}$ ) has a correlation coefficient of 0.81 (Figure 5) that exceeded the threshold of appropriate feature/attribute $(>0.70)$. Therefore, $\mathrm{Ri}$ is excluded from landslide susceptibility modeling.

\subsection{Correlation between Landslide Occurrence and Predisposing Factors}

The FR model was used to evaluate predisposing factors in order to assess the relationship between distribution of landslides and their influential factors (Table 3). The findings show that landslide frequency increases with an increase of slope values. For instance, areas with a slope less than $30^{\circ}$ and a ratio $<1$ indicate a low possibility of landslide occurrence. However, areas with slopes greater than $30^{\circ}$ and a ratio $>1$ show a high landslide possibility. Furthermore, landslide frequency decreases with an increase in elevation. At elevation $<2600 \mathrm{~m}$, the frequency ratio was $>1$, indicating a high possibility of landslide, but at elevations $>2600 \mathrm{~m}$, the ratio was $<1$, showing low possibility. With regard to distance from roads, at distances $<6000 \mathrm{~m}$, the FR was $>1$, exhibiting high possibility, but at distances $>6000 \mathrm{~m}$, FR was $<1$, showing low possibility of landslide. This implies that when proximity between a road and slope is greater, possibility of landslide incident is higher. This 
relationship is primarily due to improper cutting of a slope during road construction [82]. A higher value of SPI demonstrates a greater possibility of landslide. High SPI values reveal areas with a high potential for erosion and their association with a great possibility of landslide occurrence [83]. A higher possibility of landslide incident was found for NDVI, ranging between 0.59 and 0.91 , with an FR of 1.03 and 1.26, respectively. The lowest value of FR (0.39) was found for an NDVI between -0.2 and 0.27 . High susceptibility was found in highly vegetated areas, probably due to thick vegetation occurring in areas with steep slopes and higher elevations [42]. Faults control rock mass in a given area. Correlation between landslide occurrence and distance to faults suggests that landslide occurrence is higher in the close proximity to faults. The reason for this relationship is that both rock fractures and the degree of weathering increase near faults. These processes weaken the rocks and thus increase the likelihood of landslide [84]. Rainfall is a significant factor controlling landslide distribution in the study area. Our analysis reveals that the highest possibility of landslide occurrence was in areas with rainfall ranging between 700 and $750 \mathrm{~mm} /$ year, with higher FR values (2.89). To the best of our knowledge, this is attributable to many faults coupled with the effects of the Minjiang River and high elevation [7]. Three geology categories, i.e., Cambrian, Triassic, and Carboniferous, are dominated by high landslide susceptibility, as the frequency ratio of these subclasses exhibits 1.80, 1.12, and 1.10, respectively. The correlation between the distribution of landslide and land cover was higher in cropland and shrubland areas, as they indicate higher FR values of 2.55 and 1.08, respectively. These LC results may be attributable to poor land-use planning [42].

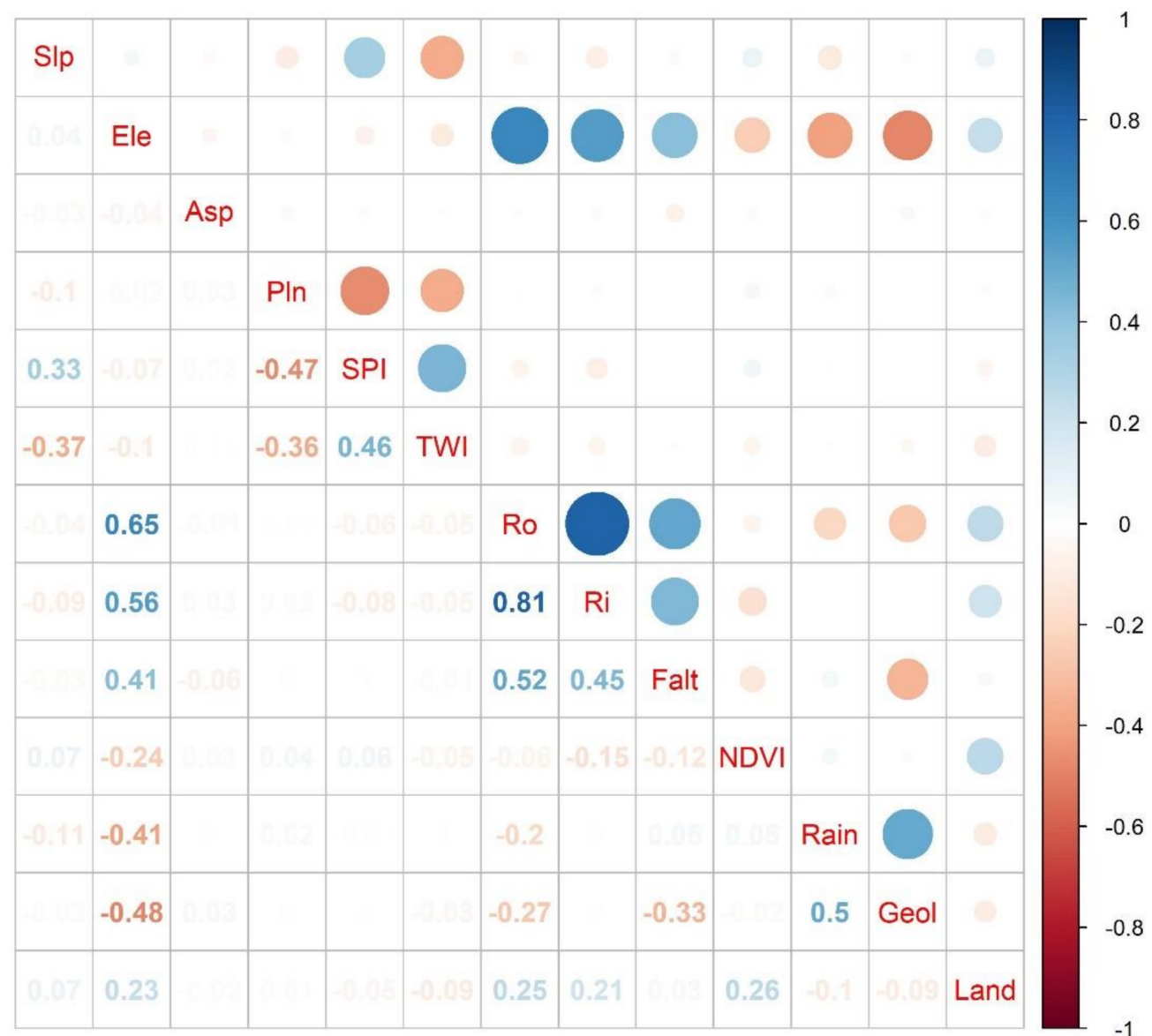

Figure 5. Feature selection results for landslide predisposing factors. (Slp: slope angle, Ele: elevation, Asp: aspect, Pln: plan curvature, SPI: stream power index, TWI: topographic wetness index, Ro: distance to roads, Ri: distance to rivers, Falt: distance to faults, NDVI: normalized difference vegetation index, Rain: rainfall, Geol: geology, and Land: land cover). 
Table 3. The relationship between landslide occurrence and each predisposing factor.

\begin{tabular}{|c|c|c|c|c|c|c|c|c|}
\hline Factor & Factor Class & $\begin{array}{l}\text { No. of Pixels } \\
\text { in Domain }\end{array}$ & $\begin{array}{l}\% \text { of } \\
\text { Domain }\end{array}$ & $\begin{array}{l}\text { No. of } \\
\text { Landslides }\end{array}$ & $\begin{array}{l}\% \text { of } \\
\text { Landslides }\end{array}$ & FR & RF & PR \\
\hline \multirow{5}{*}{$\begin{array}{l}\text { Slope } \\
\text { (degrees) }\end{array}$} & $0-15$ & 327,792 & 7.78 & 307 & 2.37 & 0.31 & 0.04 & \multirow{5}{*}{8.45} \\
\hline & $15-30$ & $1,494,388$ & 35.46 & 2344 & 18.13 & 0.51 & 0.07 & \\
\hline & $30-45$ & $1,876,163$ & 44.52 & 6644 & 51.38 & 1.15 & 0.15 & \\
\hline & $45-60$ & 491,562 & 11.66 & 3366 & 26.03 & 2.23 & 0.29 & \\
\hline & $>60$ & 24,476 & 0.58 & 270 & 2.09 & 3.60 & 0.46 & \\
\hline \multirow{5}{*}{ Elevation (m) } & $<1750$ & 261,623 & 6.21 & 2461 & 19.00 & 3.07 & 0.52 & \multirow{5}{*}{10.40} \\
\hline & $1750-2600$ & $1,039,419$ & 24.66 & 6128 & 47.40 & 1.92 & 0.33 & \\
\hline & $2600-3450$ & $1,566,899$ & 37.18 & 4096 & 31.70 & 0.85 & 0.14 & \\
\hline & $3450-4300$ & $1,194,877$ & 28.35 & 246 & 1.90 & 0.07 & 0.01 & \\
\hline & $>4300$ & 151,563 & 3.60 & 0 & 0.00 & 0.00 & 0.00 & \\
\hline \multirow{9}{*}{ Aspect } & Flat & 2586 & 0.06 & 9 & 0.10 & 1.13 & 0.12 & \multirow{9}{*}{2.14} \\
\hline & North & 489,205 & 11.61 & 834 & 6.40 & 0.56 & 0.06 & \\
\hline & Northeast & 545,870 & 12.95 & 1056 & 8.20 & 0.63 & 0.07 & \\
\hline & East & 570,251 & 13.53 & 1456 & 11.30 & 0.83 & 0.09 & \\
\hline & Southeast & 554,519 & 13.16 & 2412 & 18.70 & 1.42 & 0.15 & \\
\hline & South & 485,600 & 11.52 & 2229 & 17.20 & 1.50 & 0.16 & \\
\hline & Southwest & 491,043 & 11.65 & 2260 & 17.50 & 1.50 & 0.16 & \\
\hline & West & 526,368 & 12.49 & 1805 & 14.00 & 1.12 & 0.12 & \\
\hline & Northwest & 548,572 & 13.02 & 870 & 6.70 & 0.50 & 0.06 & \\
\hline \multirow{3}{*}{$\begin{array}{l}\text { Plan } \\
\text { curvature }\end{array}$} & $<-1($ concave $)$ & 649,075 & 15.40 & 2174 & 16.80 & 1.09 & 0.36 & \multirow{3}{*}{1.00} \\
\hline & 0 & $1,474,554$ & 34.99 & 4251 & 32.90 & 0.94 & 0.31 & \\
\hline & >1(Convex) & $2,090,752$ & 49.61 & 6506 & 50.30 & 1.01 & 0.33 & \\
\hline \multirow{5}{*}{ SPI } & $0-5$ & $1,159,179$ & 27.51 & 3061 & 23.70 & 0.86 & 0.26 & \multirow{5}{*}{4.46} \\
\hline & $5-10$ & 44,171 & 1.05 & 51 & 0.40 & 0.38 & 0.11 & \\
\hline & $10-15$ & 113,106 & 2.68 & 134 & 1.00 & 0.39 & 0.12 & \\
\hline & $15-20$ & 165,664 & 3.93 & 302 & 2.30 & 0.59 & 0.18 & \\
\hline & $>20$ & $2,732,261$ & 64.83 & 9383 & 72.60 & 1.12 & 0.34 & \\
\hline \multirow{5}{*}{ TWI } & $<4$ & 657,487 & 15.60 & 2873 & 22.20 & 1.42 & 0.31 & \multirow{5}{*}{4.38} \\
\hline & $4-6$ & $2,290,162$ & 54.34 & 6515 & 50.40 & 0.93 & 0.20 & \\
\hline & $6-8$ & 913,555 & 21.68 & 2790 & 21.60 & 1.00 & 0.22 & \\
\hline & $8-10$ & 253,173 & 6.01 & 623 & 4.80 & 0.80 & 0.18 & \\
\hline & $>10$ & 100,004 & 2.37 & 130 & 1.00 & 0.42 & 0.09 & \\
\hline \multirow{7}{*}{$\begin{array}{l}\text { Distance to } \\
\text { roads }(\mathrm{m})\end{array}$} & $0-1000$ & 352,201 & 8.36 & 4238 & 32.80 & 3.92 & 0.38 & \multirow{7}{*}{5.60} \\
\hline & $1000-2000$ & 320,976 & 7.62 & 2698 & 20.90 & 2.74 & 0.27 & \\
\hline & $2000-3000$ & 311,409 & 7.39 & 1310 & 10.10 & 1.37 & 0.13 & \\
\hline & $3000-4000$ & 301,292 & 7.15 & 979 & 7.60 & 1.06 & 0.10 & \\
\hline & $4000-6000$ & 559,651 & 13.28 & 1973 & 15.30 & 1.15 & 0.11 & \\
\hline & $6000-8000$ & $4,558,441$ & 10.82 & 835 & 6.50 & 0.60 & 0.06 & \\
\hline & $>8000$ & $1,913,007$ & 45.39 & 898 & 6.90 & 0.15 & 0.01 & \\
\hline \multirow{5}{*}{$\begin{array}{l}\text { Distance to } \\
\text { faults (m) }\end{array}$} & & 859,855 & 20.40 & 9337 & 72.20 & 3.54 & 0.66 & \multirow{5}{*}{12.97} \\
\hline & $0-20002000-4000$ & 660,187 & 15.67 & 2282 & 17.60 & 1.13 & 0.21 & \\
\hline & $4000-6000$ & 516,426 & 12.25 & 570 & 4.40 & 0.36 & 0.07 & \\
\hline & $6000-8000$ & 383,974 & 9.11 & 252 & 1.90 & 0.21 & 0.04 & \\
\hline & $>8000$ & $1,793,939$ & 42.57 & 490 & 3.80 & 0.09 & 0.02 & \\
\hline \multirow{5}{*}{ NDVI } & $-0.20-0.27$ & 115,241 & 2.73 & 138 & 1.07 & 0.39 & 0.10 & \\
\hline & $0.27-0.44$ & 275,557 & 6.54 & 574 & 4.44 & 0.68 & 0.17 & \\
\hline & $0.44-0.59$ & 822,723 & 19.52 & 1612 & 12.47 & 0.64 & 0.16 & 4.34 \\
\hline & $0.59-0.70$ & $1,385,952$ & 32.89 & 4376 & 33.84 & 1.03 & 0.26 & \\
\hline & $0.70-0.91$ & $1,614,908$ & 38.32 & 6231 & 48.19 & 1.26 & 0.31 & \\
\hline & $<700$ & 178,320 & 4.23 & 252 & 1.95 & 0.46 & 0.09 & \\
\hline & $700-750$ & 668,284 & 15.86 & 5935 & 45.90 & 2.89 & 0.56 & \\
\hline Rainfall & $750-800$ & $1,096,458$ & 26.02 & 1457 & 11.27 & 0.43 & 0.08 & 9.58 \\
\hline & $800-850$ & $1,905,695$ & 45.22 & 4659 & 36.03 & 0.80 & 0.15 & \\
\hline & $>850$ & 365,624 & 8.68 & 628 & 4.86 & 0.56 & 0.11 & \\
\hline
\end{tabular}


Table 3. Cont.

\begin{tabular}{|c|c|c|c|c|c|c|c|c|}
\hline Factor & Factor Class & $\begin{array}{l}\text { No. of Pixels } \\
\text { in Domain }\end{array}$ & $\begin{array}{l}\% \text { of } \\
\text { Domain }\end{array}$ & $\begin{array}{l}\text { No. of } \\
\text { Landslides }\end{array}$ & $\begin{array}{l}\% \text { of } \\
\text { Landslides }\end{array}$ & FR & $\mathbf{R F}$ & PR \\
\hline \multirow{8}{*}{ Geology } & Triassic & $1,875,665$ & 44.50 & 6428 & 49.71 & 1.12 & 0.18 & \multirow{8}{*}{5.67} \\
\hline & Mesoproterozoic & 41,842 & 0.99 & 0 & 0.00 & 0.00 & 0.00 & \\
\hline & Permian & 100,055 & 2.37 & 300 & 2.32 & 0.98 & 0.15 & \\
\hline & Cretaceous & 606,215 & 14.38 & 923 & 7.14 & 0.50 & 0.08 & \\
\hline & Carboniferous & $1,206,402$ & 28.62 & 4057 & 31.37 & 1.10 & 0.17 & \\
\hline & Ordovician & 176,153 & 4.18 & 391 & 3.02 & 0.72 & 0.11 & \\
\hline & Cambrian & 144,813 & 3.44 & 801 & 6.19 & 1.80 & 0.28 & \\
\hline & Neoproterozoic & 63,705 & 1.51 & 31 & 0.24 & 0.16 & 0.02 & \\
\hline \multirow{7}{*}{ Land cover } & \multirow{7}{*}{$\begin{array}{l}\text { Cropland } \\
\text { Shrub land } \\
\text { Tree cover } \\
\text { Grassland } \\
\text { Built-up area } \\
\text { Waterbodies } \\
\text { Snow and ice } \\
\text { cover }\end{array}$} & 186,651 & 4.43 & 1460 & 11.29 & 2.55 & 0.45 & \multirow{7}{*}{8.91} \\
\hline & & 229,970 & 5.46 & 761 & 5.89 & 1.08 & 0.19 & \\
\hline & & $3,318,735$ & 78.75 & 9601 & 74.25 & 0.94 & 0.16 & \\
\hline & & 471,725 & 11.19 & 1105 & 8.55 & 0.76 & 0.13 & \\
\hline & & 3181 & 0.08 & 3 & 0.02 & 0.31 & 0.05 & \\
\hline & & 3558 & 0.08 & 1 & 0.01 & 0.09 & 0.02 & \\
\hline & & 547 & 0.01 & 0 & 0.00 & 0.00 & 0.00 & \\
\hline
\end{tabular}

\subsection{Landslide Susceptibility Map}

Four landslide susceptibility maps are constructed, based on a combination of the 12 predisposing factors, using four deep learning algorithms. The resultant maps are then manually categorized, as shown in Figure 6. Figure 6 illustrates those areas along the rivers, mainly the Minjiang River and southeastern portions of the study area are most vulnerable to landslides. The percentage of specific landslide susceptibility classes is summarized in Figure 7.

Based on historical meteorological data and information recorded during field visits, landslides in Maoxian most commonly occur during the rainy season (May to September). For instance, on 24 June 2017, the "Xinmo landslide" occurred in the village of Xinmo in the town of Diexi, caused 83 fatalities, and destroyed 67 houses [85]. In addition, on 25 July 2020, a flash landslide debris flow killed two people and destroyed houses in Jiaoyuan village of Weimen town. These landslides occurred in the rainy season, indicating that rainfall is one of the main factors contributing to the occurrence of landslides in the area under investigation. According to major predisposing factors results, distribution of landslides in the most highly susceptible areas was attributable to historical earthquakes, expansion of the Minjiang River and its tributaries due to flooding associated with heavy rainfall, inappropriate land-use practices such as farming, and road construction, which contribute to slope failure and eventually result in a landslide event. Unsustainable human activities, such as those listed above, accelerate the risk of landslides and can lead to extensive property damage and loss of life. Therefore, mitigation measures have to be taken for areas with very high levels of landslide susceptibility. In addition, public should be informed about the susceptibility of future landslide occurrence to help them safeguard their lives and properties. Significantly early warning systems must be strengthened and distributed to the areas highly prone to landslides.

\subsection{Model Validation of the Landslide Susceptibility Maps}

Based on the training dataset, the success rates for the CNN, DNN, LSTM, and RNN algorithms were $0.866,0.877,0.883$, and 0.845 , respectively (Figure 8a). By employing the testing datasets, prediction rates for the CNN, DNN, LSTM, and RNN algorithms are found to be $0.856,0.873,0.865$, and 0.829 , respectively (Figure $8 \mathrm{~b}$ ). This explains why the prediction accuracy of the DNN algorithm $(87.30 \%)$ is higher than that of CNN $(85.60 \%)$, LSTM $(86.50 \%)$, and RNN (82.90\%). Therefore, it is reasonable to conclude that the DNN 
algorithm is a better predictive model for mapping landslide susceptibility and can be useful in other areas of similar environments.
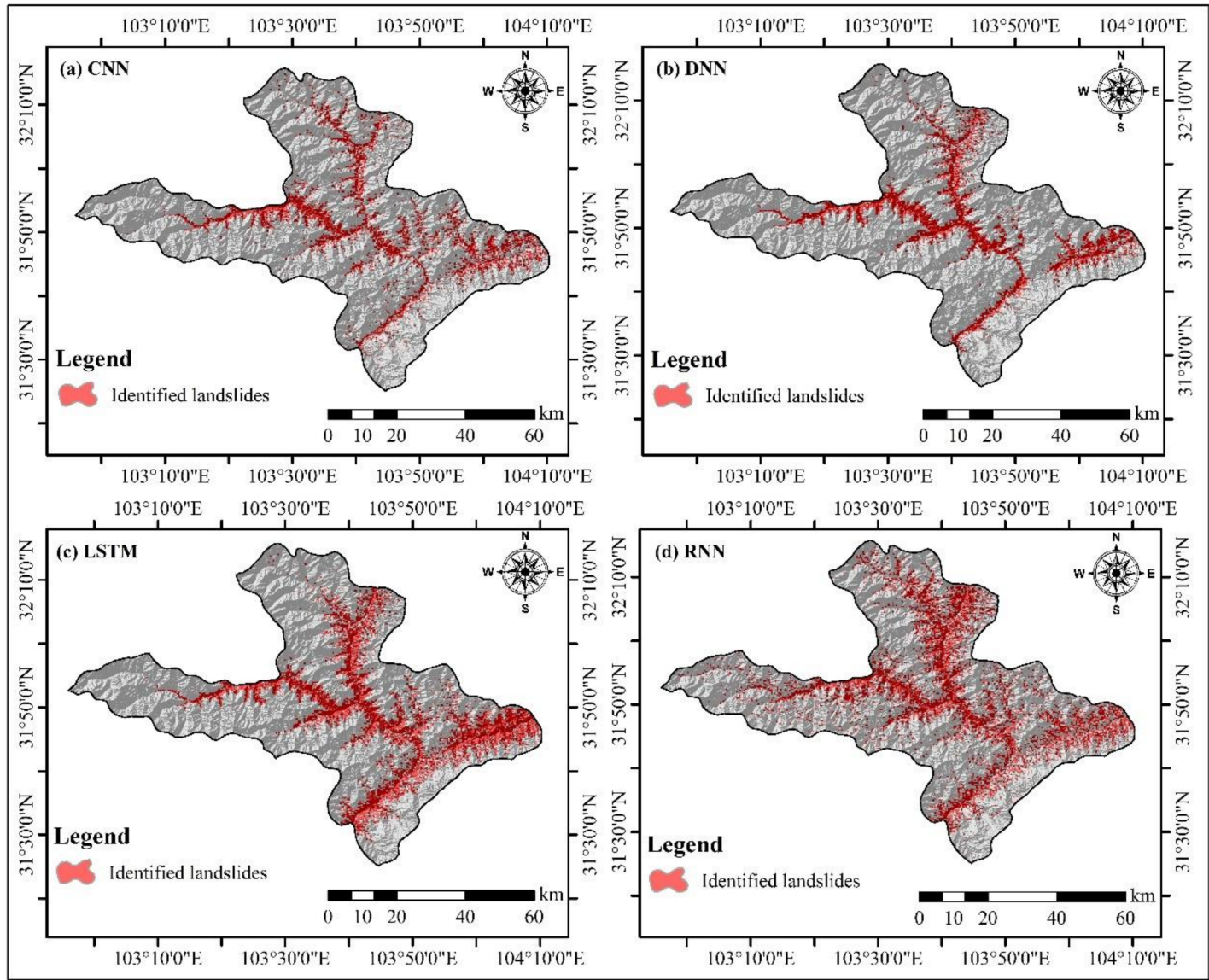

Figure 6. Landslide susceptibility maps of the study area produced via (a) CNN, (b) DNN, (c) LSTM, and (d) RNN.

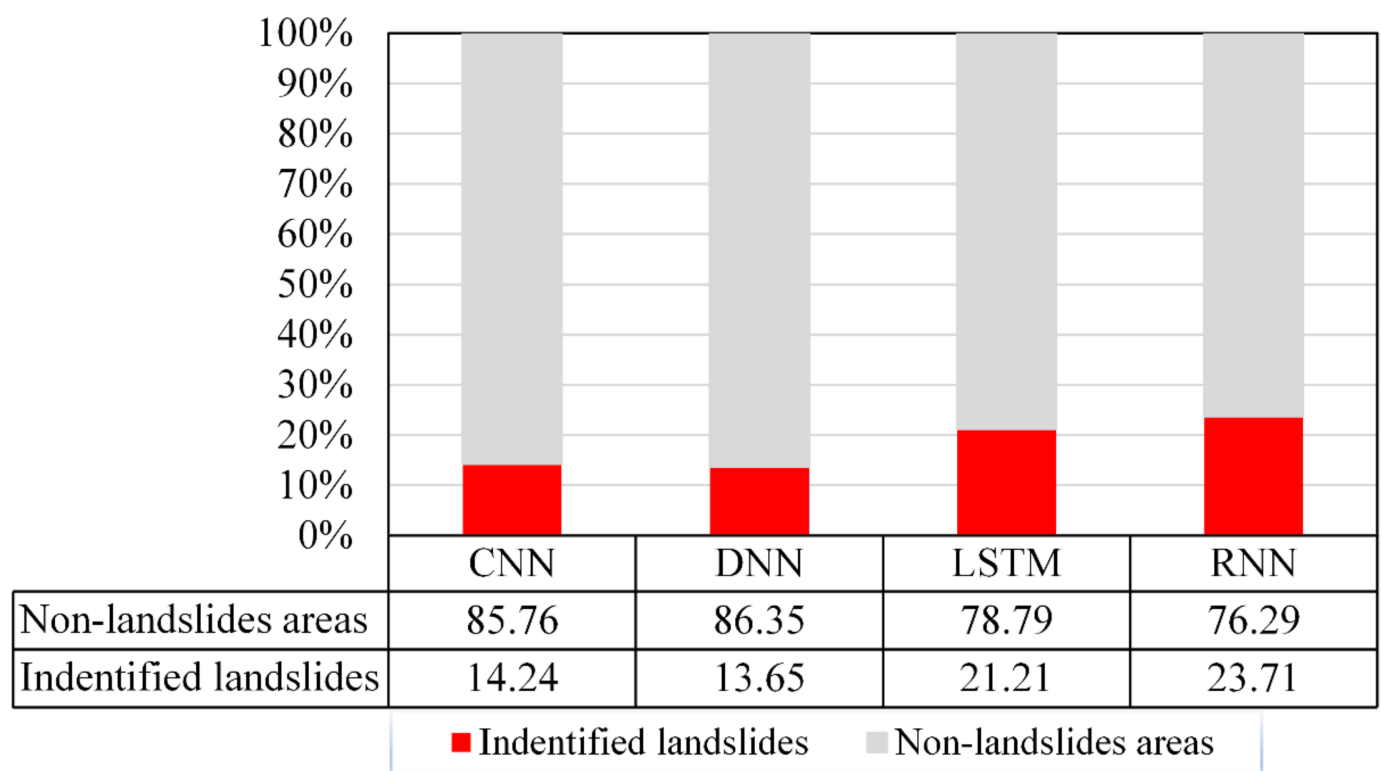

Figure 7. Model-wise landslide percentage in the study area. 
(a) Training dataset

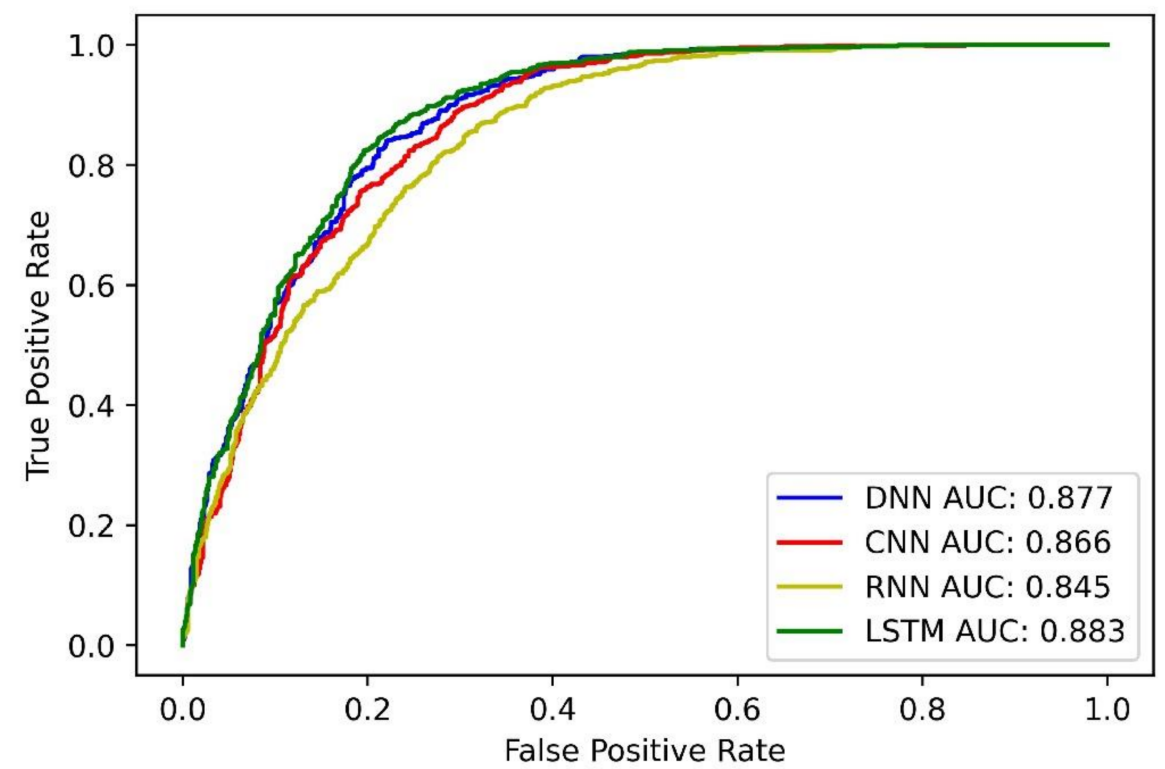

(b) Testing dataset

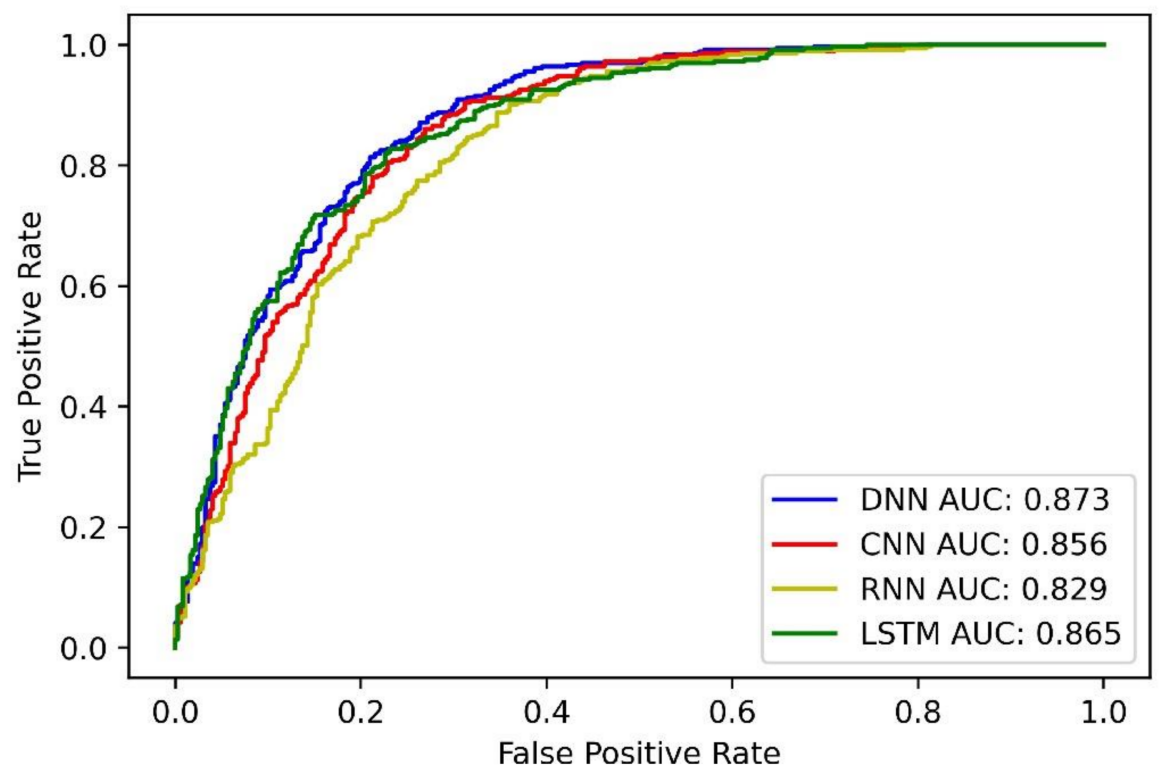

Figure 8. AUC for LSMs of the FR and LR models: (a) success rate curves and (b) prediction rate curves.

Recall, F1-score, and log-loss statistical indices were used to evaluate the performance of four deep learning methods (Table 4). Results revealed that DNN algorithm predicted the possibility of landslide event better than the other methods.

Table 4. Statistical indices for algorithm evaluation.

\begin{tabular}{ccccccccc}
\hline \multirow{2}{*}{ Algorithm } & \multicolumn{4}{c}{ Training Dataset } & \multicolumn{4}{c}{ Testing Dataset } \\
\cline { 2 - 10 } & Recall & F1 Score & AUC & Log-Loss & Recall & F1 Score & AUC & Log-Loss \\
\hline CNN & 0.790 & 0.788 & 0.866 & 0.449 & 0.803 & 0.789 & 0.856 & 0.496 \\
DNN & 0.943 & 0.828 & 0.877 & 0.440 & 0.838 & 0.805 & 0.873 & 0.438 \\
LSTM & 0.856 & 0.826 & 0.883 & 0.423 & 0.888 & 0.801 & 0.865 & 0.491 \\
RNN & 0.921 & 0.804 & 0.845 & 0.479 & 0.833 & 0.777 & 0.829 & 0.848 \\
\hline
\end{tabular}




\subsection{Validation of the Landslide Susceptibility Map}

The resulting LSM (Figure 6b) is further compared with photographs taken during field visits. Figure 9 displays landslides observed along the Minjiang River. This result is in accordance with the produced susceptibility map as both show that areas along the rivers are most susceptible to landslides.

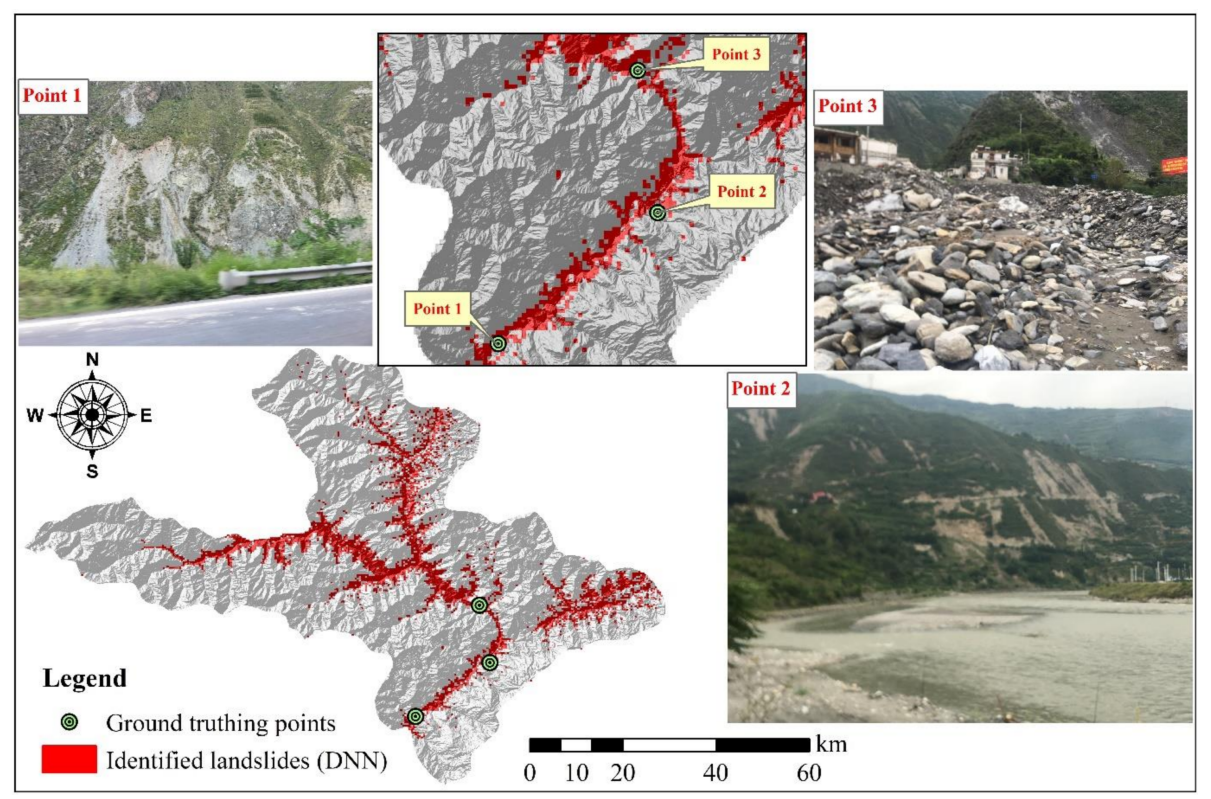

Figure 9. Comparison of DNN-based landslide susceptibility map with a field visit.

\subsection{Identifying Most Important Factors}

The results indicated that slope was the most important factor $(\beta=0.252)$, followed by rainfall ( $\beta=0.110)$ and distance to faults $(\beta=0.102)$ (Table 5). In contrast, TWI and NDVI showed no significant contribution $(\beta=0.00)$ in influencing landslides distribution in the study area.

Table 5. Regression result, showing most effective predisposing factors.

\begin{tabular}{|c|c|c|c|c|c|c|c|}
\hline Factor & $\begin{array}{c}\text { Regression } \\
\text { Coefficient, } \beta\end{array}$ & $\begin{array}{l}\text { Standard } \\
\text { Error }\end{array}$ & $\mathbf{t}$ & $\operatorname{Pr}>|t|$ & $\begin{array}{c}\text { Lower } \\
\text { Bound }(95 \%)\end{array}$ & $\begin{array}{c}\text { Upper } \\
\text { Bound }(95 \%)\end{array}$ & Rank \\
\hline Slope angle & 0.252 & 0.017 & 14.902 & $<0.0001$ & 0.218 & 0.285 & 1 \\
\hline Rainfall & 0.110 & 0.019 & 5.859 & $<0.0001$ & 0.073 & 0.147 & 2 \\
\hline Distance to faults & 0.102 & 0.020 & 4.995 & $<0.0001$ & 0.062 & 0.141 & 3 \\
\hline Plan curvature & 0.034 & 0.018 & 1.924 & 0.054 & -0.001 & 0.069 & 4 \\
\hline Aspect & -0.027 & 0.016 & -1.726 & 0.085 & -0.058 & 0.004 & 5 \\
\hline Distance to roads & -0.079 & 0.023 & -3.500 & 0.000 & -0.124 & -0.035 & 6 \\
\hline Geology & -0.110 & 0.021 & -5.345 & $<0.0001$ & -0.150 & -0.070 & 7 \\
\hline SPI & -0.112 & 0.020 & -5.576 & $<0.0001$ & -0.151 & -0.072 & 8 \\
\hline Land cover & -0.134 & 0.017 & -8.104 & $<0.0001$ & -0.167 & -0.102 & 9 \\
\hline Elevation & -0.521 & 0.024 & -22.060 & $<0.0001$ & -0.567 & -0.475 & 1 \\
\hline TWI & 0.000 & 0.000 & - & - & - & - & 11 \\
\hline NDVI & 0.000 & 0.000 & - & - & - & - & 12 \\
\hline
\end{tabular}




\subsection{Trigger Mechanisms of Landslides in Moaxian County}

Rainfall is one of the key factors triggering landslides in China [5]. Analysis in this study shows that slope, rainfall, and distance to faults are the main triggering factors in Maoxian. These results are in accordance with those of a previous study [36], which indicates that dynamic faults (fault motion) are the most significant factors of landslide formation in Moaxian and that rainfall acts as an inducing factor. In fact, Maoxian is situated in the Longmenshan faults belt, which is an area that is highly susceptible to landslide occurrence [5]. Both rock fractures and the degree of weathering increase closer to the faults, weakening the rocks nearby faults [84]. This damage leads to a reduction in rock strength due to the build-up of cracks and slipped surfaces [35]. Moreover, when rainfall exceeds groundwater drainage, pore water pressure develops within the cracks governed by the discontinuities, triggering landslide events. In addition, erosion caused by rainfall and seismic effects contributes to the extension of fractures and slope instability [9].

In the study area, active faults and intensive tectonic processes control rock mass aspects and rock mass discontinuities [11]. Based on these explanations, the triggering mechanism of landslides in the study area may be explained as: rainfall first softens the sliding zone, then penetrates the cracks of the rock mass, and finally increases the weight of the rock mass, which leads to slope failure. The weight of the rock mass probably increases through the development of a perched water table and the build-up of pore water pressure, which are hydrological processes resulting from rainfall. This has been corroborated by Kasim et al. [86], who show that rainfall increases water content and pore water pressures within a soil or rock mass, which can trigger landslide occurrence. We observed open cracks on some slopes during the field visits, indicating these hillslopes may transform into landslides in the future as faults or rainfall events are dynamic in nature.

\section{Conclusions and Future Work}

This study assessed landslide susceptibility in Maoxian County, Sichuan, China, based on CNN, DNN, LSTM, and RNN deep learning algorithms. A landslide inventory map of the study area was generated on the basis of historical data, remote sensing techniques, and field observations. Furthermore, 12 different conditioning factors were considered. The results revealed that slope, rainfall, and distance to faults are the most significant factors controlling landslide distribution in Maoxian. The maps produced here indicated that high landslide susceptibility zones are located in low-elevation river channel areas (mainly those of the Minjiang River and its tributaries), where soil is saturated and surface is exposed, and also in the southeastern part of the study area.

The susceptibility maps developed by four deep learning algorithms were validated and proven to have a high accuracy as AUC showed $>82.00 \%$ agreement. Prediction suggested that the DNN (AUC > 87.30\% with training and testing datasets) model performed better than the other three algorithms. However, the other three algorithms, i.e., CNN, LSTM, and RNN can be used in predicting landslide susceptibility as they are performing quite similar with DNN. Although the resultant maps indicated the spatial dissemination of landslides, one limitation of this study was that they could not predict time, degree, or frequency of landslide occurrences. Moreover, a hybrid assembled deep learning algorithm should be tested and applied in future work in the study area for LSM.

The resultant LSMs can provide essential and valuable information to policy-makers, and engineers for slope stability analysis, sustainable land-use plan, infrastructure development (to stop the growth of certain projects, i.e., towns, roads, and tourist sites in the future in the highly susceptible areas), and establishment of landslide mitigation measures in the studied area.

Author Contributions: Conceptualization, methodology, writing-original draft, J.M.H.; supervision, writing-review and editing, funding acquisition, project administration, N.C.; conceptualization, methodology, formal analysis, writing-original draft, data curation, software, validation, M.R.; 
supervision, writing-review and editing, M.M.I. and A.D.; software, validation, H.A., A.E., G.S. and S.N.L. All authors have read and agreed to the published version of the manuscript.

Funding: This research was funded by the National Natural Science Foundation of China (Grant Nos. 41861134008), the Second Tibetan Plateau Scientific Expedition and Research Program (STEP) of China (Grant no. 2019QZKK0902), the National Key Research and Development Program of China (Project no. 2018YFC1505202), and the Key R\&D Projects of Sichuan Science and Technology (Grant no. 18ZDYF0329).

Institutional Review Board Statement: Not applicable.

Informed Consent Statement: Not applicable.

Data Availability Statement: Data are available upon request from the corresponding author.

Acknowledgments: The authors would like to express gratitude to the University of Chinese Academy of Sciences and the Institute of Mountain Hazards and Environment, Chinese Academy of Sciences for their financial assistance.The authors would also like to acknowledge and appreciate Sichuan provincial administration officials for providing with us the historical landslide data of Maoxian County; without these data, this work would not have been accomplished.

Conflicts of Interest: The authors declare no conflict of interest.

\section{References}

1. Stanley, T.; Kirschbaum, D.B. A heuristic approach to global landslide susceptibility mapping. Nat. Hazards 2017, 87, 145-164. [CrossRef] [PubMed]

2. Das, G.; Lepcha, K. Application of logistic regression (LR) and frequency ratio (FR) models for landslide susceptibility mapping in Relli Khola river basin of Darjeeling Himalaya, India. SN Appl. Sci. 2019, 1, 1453. [CrossRef]

3. Klose, M.; Maurischat, P.; Damm, B. Landslide impacts in Germany: A historical and socioeconomic perspective. Landslides 2016, 13, 183-199. [CrossRef]

4. Nahayo, L.; Mupenzi, C.; Habiyaremye, G.; Kalisa, E.; Udahogora, M.; Nzabarinda, V.; Li, L. Landslides Hazard Mapping in Rwanda Using Bivariate Statistical Index Method. Environ. Eng. Sci. 2019, 36, 892-902. [CrossRef]

5. Qiu, J.; Wang, X.; He, S.; Liu, H.; Lai, J.; Wang, L. The catastrophic landside in Maoxian County, Sichuan, SW China, on June 24, 2017. Nat. Hazards 2017, 89, 1485-1493. [CrossRef]

6. $\quad$ Ouyang, C.J.; Zhao, W.; He, S.M.; Wang, D.P.; Zhou, S.; An, H.C.; Wang, Z.W.; Cheng, D.X. Numerical modeling and dynamic analysis of the 2017 Xinmo landslide in Maoxian County, China. J. Mt. Sci. 2017, 14, 1701-1711. [CrossRef]

7. Fan, J.R.; Zhang, X.Y.; Su, F.H.; Ge, Y.G.; Tarolli, P.; Yang, Z.Y.; Zeng, C.; Zeng, Z. Geometrical feature analysis and disaster assessment of the Xinmo landslide based on remote sensing data. J. Mt. Sci. 2017, 14, 1677-1688. [CrossRef]

8. Yong, C.; Jinlong, D.; Fei, G.; Bin, T.; Tao, Z.; Hao, F.; Li, W.; Qinghua, Z. Review of Landslide Susceptibility Assessment Based on Knowledge Mapping. Stochastic Environ. Res. Risk Assess. 2022, 2022, 1-19. [CrossRef]

9. Su, L.J.; Hu, K.H.; Zhang, W.F.; Wang, J.; Lei, Y.; Zhang, C.L.; Cui, P.; Pasuto, A.; Zheng, Q.H. Characteristics and triggering mechanism of Xinmo landslide on 24 June 2017 in Sichuan, China. J. Mt. Sci. 2017, 14, 1689-1700. [CrossRef]

10. Fan, X.; Xu, Q.; Scaringi, G.; Dai, L.; Li, W.; Dong, X.; Zhu, X.; Pei, X.; Dai, K.; Havenith, H.B. Failure mechanism and kinematics of the deadly June 24th 2017 Xinmo landslide, Maoxian, Sichuan, China. Landslides 2017, 14, 2129-2146. [CrossRef]

11. Chen, K.T.; Wu, J.H. Simulating the failure process of the Xinmo landslide using discontinuous deformation analysis. Eng. Geol. 2018, 239, 269-281. [CrossRef]

12. Ding, M.; Huang, T.; Zheng, H.; Yang, G. Respective influence of vertical mountain differentiation on debris flow occurrence in the Upper Min River, China. Sci. Rep. 2020, 10, 11689. [CrossRef] [PubMed]

13. Ding, M.; Tang, C.; Huang, T.; Gao, Z. Dynamic vulnerability analysis of mountain settlements exposed to geological hazards: A case study of the upper Min River, China. Adv. Civ. Eng. 2020, 2020, 8887487. [CrossRef]

14. Yan, Y.; Cui, Y.; Guo, J.; Hu, S.; Wang, Z.; Yin, S. Landslide reconstruction using seismic signal characteristics and numerical simulations: Case study of the 2017 "6.24" Xinmo landslide. Eng. Geol. 2020, 270, 105582. [CrossRef]

15. Lucchese, L.V.; de Oliveira, G.G.; Pedrollo, O.C. Attribute selection using correlations and principal components for artificial neural networks employment for landslide susceptibility assessment. Environ. Monit. Assess 2020, 192, 129. [CrossRef] [PubMed]

16. Yan, F.; Zhang, Q.; Ye, S.; Ren, B. A novel hybrid approach for landslide susceptibility mapping integrating analytical hierarchy process and normalized frequency ratio methods with the cloud model. Geomorphology 2019, 327, 170-187. [CrossRef]

17. Moharrami, M.; Naboureh, A.; Gudiyangada Nachappa, T.; Ghorbanzadeh, O.; Guan, X.; Blaschke, T. National-Scale Landslide Susceptibility Mapping in Austria Using Fuzzy Best-Worst Multi-Criteria Decision-Making. ISPRS Int. J. Geo-Inf. 2020, 9, 393. [CrossRef]

18. Masrur, A.; Yu, M.; Luo, W.; Dewan, A. Space-time patterns, change, and propagation of COVID-19 risk relative to the intervention scenarios in Bangladesh. Int. J. Environ. Res. Public Health 2020, 17(16), 5911. [CrossRef] 
19. Kawamura, Y.; Dewan, A.M.; Veenendaal, B.; Hayashi, M.; Shibuya, T.; Kitahara, I.; Nobuhara, H.; Ishii, K. Using GIS to develop a mobile communications network for disaster-damaged areas. Int. J. Digital Earth 2014, 7, 279-293. [CrossRef]

20. Wang, Q.; Li, W.; Wu, Y.; Pei, Y.; Xie, P. Application of statistical index and index of entropy methods to landslide susceptibility assessment in Gongliu (Xinjiang, China). Environ. Earth Sci. 2016, 75, 599. [CrossRef]

21. Dou, J.; Yamagishi, H.; Zhu, Z.; Yunus, A.P.; Chen, C.W. TXT-tool 1.081-6.1 A comparative study of the Binary Logistic Regression (BLR) and Artificial Neural Network (ANN) models for GIS-based spatial predicting landslides at a regional scale. In Landslide Dynamics: ISDR-ICL Landslide Interactive Teaching Tools; Springer: Cham, Switzerland, 2017; Volume 1, pp. 139-151. [CrossRef]

22. Gong, Q.; Zhang, J.; Wang, J. Application of GIS-Based Back Propagation Artificial Neural Networks and Logistic Regression for shallow Landslide Susceptibility Mapping in South China-Take Meijiang River Basin as an Example. Open Civ. Eng. J. 2018, 12, 21-34. [CrossRef]

23. Mandal, S.; Mondal, S. Artificial Neural Network (ANN) Model and Landslide Susceptibility. In Statistical Approaches for Landslide Susceptibility Assessment and Prediction; Springer: Cham, Switzerland, 2018; pp. 1-193. [CrossRef]

24. Lee, S.; Lee, M.J.; Jung, H.S.; Lee, S. Landslide susceptibility mapping using Naïve Bayes and Bayesian network models in Umyeonsan, Korea. Geocarto Int. 2019, 35, 1665-1679. [CrossRef]

25. Polykretis, C.; Chalkias, C.; Ferentinou, M. Adaptive neuro-fuzzy inference system (ANFIS) modeling for landslide susceptibility assessment in a Mediterranean hilly area. Bull. Eng. Geol. Environ. 2019, 78, 1173-1187. [CrossRef]

26. Shirvani, Z. A holistic analysis for landslide susceptibility mapping applying geographic object-based random forest: A comparison between protected and non-protected forests. Remote Sens. 2020, 12, 434. [CrossRef]

27. Yi, Y.; Zhang, Z.; Zhang, W.; Jia, H.; Zhang, J. Landslide susceptibility mapping using multiscale sampling strategy and convolutional neural network: A case study in Jiuzhaigou region. Catena 2020, 195, 104851. [CrossRef]

28. Zhao, W.; Du, S. Learning multiscale and deep representations for classifying remotely sensed imagery. ISPRS J. Photogramm. Remote Sens. 2016, 113, 155-165. [CrossRef]

29. Paoletti, M.E.; Haut, J.M.; Plaza, J.; Plaza, A. A new deep convolutional neural network for fast hyperspectral image classification. ISPRS J. Photogramm. Remote Sens. 2018, 145, 120-147. [CrossRef]

30. Zhang, L.J.; Tang, Y.; Liu, B.H. Changes in agricultural system as farmers adapt to economic-social and climatic changes in the min upriver rural areas in western Sichuan, southwestern China. J. Mt. Sci. 2015, 12, 747-758. [CrossRef]

31. Jiang, H.; Mao, X.; Xu, H.; Yang, H.; Ma, X.; Zhong, N.; Li, Y. Provenance and earthquake signature of the last deglacial Xinmocun lacustrine sediments at Diexi, East Tibet. Geomorphology 2014, 204, 518-531. [CrossRef]

32. Intrieri, E.; Raspini, F.; Fumagalli, A.; Lu, P.; Del Conte, S.; Farina, P.; Allievi, J.; Ferretti, A.; Casagli, N. The Maoxian landslide as seen from space: Detecting precursors of failure with Sentinel-1 data. Landslides 2018, 15, 123-133. [CrossRef]

33. Partap, U.; Ya, T. The human pollinators of fruit crops in Maoxian County, Sichuan, China. Mt. Res. Dev. 2012, 32, 176-186. [CrossRef]

34. Wang, Y.; Zhao, B.; Li, J. Mechanism of the catastrophic June 2017 landslide at Xinmo Village, Songping River, Sichuan Province, China. Landslides 2018, 15, 333-345. [CrossRef]

35. Zhao, S.; Chigira, M.; Wu, X. Buckling deformations at the 2017 Xinmo landslide site and nearby slopes, Maoxian, Sichuan, China. Eng. Geol. 2018, 246, 187-197. [CrossRef]

36. Shao, C.; Li, Y.; Lan, H.; Li, P.; Zhou, R.; Ding, H.; Yan, Z.; Dong, S.; Yan, L.; Deng, T. The role of active faults and sliding mechanism analysis of the 2017 Maoxian postseismic landslide in Sichuan, China. Bull. Eng. Geol. Environ. 2019, 78, 5635-5651. [CrossRef]

37. Zhang, S. Geological Formation Names of China (1866-2000); Springer: Berlin/Heidelberg, Germany, 2009.

38. Qi, S.; Xu, Q.; Lan, H.; Zhang, B.; Liu, J. Spatial distribution analysis of landslides triggered by 2008.5.12 Wenchuan Earthquake, China. Eng. Geol. 2010, 116, 95-108. [CrossRef]

39. Wieczorek, G.F. Preparing a Detailed Landslide-Inventory Map for Hazard Evaluation and Reduction. Bull. Assoc. Eng. Geol. 1984, 21, 337-342. [CrossRef]

40. Shahabi, H.; Khezri, S.; Ahmad, B.B.; Hashim, M. Landslide susceptibility mapping at central Zab basin, Iran: A comparison between analytical hierarchy process, frequency ratio and logistic regression models. Catena 2014, 115, 55-70. [CrossRef]

41. Wang, Q.; Li, W.; Chen, W.; Bai, H. GIS-based assessment of landslide susceptibility using certainty factor and index of entropy models for the Qianyang county of Baoji city, China. J. Earth Syst. Sci. 2015, 124, 1399-1415. [CrossRef]

42. Mind'je, R.; Li, L.; Nsengiyumva, J.B.; Mupenzi, C.; Nyesheja, E.M.; Kayumba, P.M.; Gasirabo, A.; Hakorimana, E. Landslide susceptibility and influencing factors analysis in Rwanda. Environ. Dev. Sustain. 2019, 22, 7985-8012. [CrossRef]

43. Tang, R.X.; Kulatilake, P.H.S.W.; Yan, E.C.; Cai, J. Evaluating landslide susceptibility based on cluster analysis, probabilistic methods, and artificial neural networks. Bull. Eng. Geol. Environ. 2020, 79, 2235-2254. [CrossRef]

44. Intarawichian, N.; Dasananda, S. Frequency ratio model based landslide susceptibility mapping in lower Mae Chaem watershed, Northern Thailand. Environ. Earth Sci. 2011, 64, 2271-2285. [CrossRef]

45. Vijith, H.; Madhu, G. Estimating potential landslide sites of an upland sub-watershed in Western Ghat's of Kerala (India) through frequency ratio and GIS. Environ. Geol. 2008, 55, 1397-1405. [CrossRef]

46. Kayastha, P. Landslide susceptibility mapping and factor effect analysis using frequency ratio in a catchment scale: A case study from Garuwa sub-basin, East Nepal. Arab. J. Geosci. 2015, 8, 8601-8613. [CrossRef] 
47. Nefeslioglu, H.A.; Duman, T.Y.; Durmaz, S. Landslide susceptibility mapping for a part of tectonic Kelkit Valley (Eastern Black Sea region of Turkey). Geomorphology 2008, 94, 401-418. [CrossRef]

48. Yilmaz, C.; Topal, T.; Süzen, M. GIS-based landslide susceptibility mapping using bivariate statistical analysis in Devrek (Zonguldak-Turkey). Environ. Earth Sci. 2012, 65, 2161-2178. [CrossRef]

49. Sørensen, R.; Zinko, U.; Seibert, J. On the calculation of the topographic wetness index: Evaluation of different methods based on field observations. Hydrol. Earth Syst. Sci. 2006, 10, 101-112. [CrossRef]

50. Acharya, T.D.; Lee, D.H. Landslide Susceptibility Mapping using Relative Frequency and Predictor Rate along Araniko Highway. Ksce J. Civ. Eng. 2018, 23, 763-776. [CrossRef]

51. Myronidis, D.; Papageorgiou, C.; Theophanous, S. Landslide susceptibility mapping based on landslide history and analytic hierarchy process (AHP). Nat. Hazards 2016, 81, 245-263. [CrossRef]

52. Meng, W.; Xu, Y.; Cheng, W.C.; Arulrajah, A. Landslide event on 24 june in sichuan province, China: Preliminary investigation and analysis. Geosciences 2018, 8, 39. [CrossRef]

53. Vojteková, J.; Vojtek, M. Assessment of landslide susceptibility at a local spatial scale applying the multi-criteria analysis and GIS: A case study from Slovakia. Geomat. Nat. Hazards Risk 2020, 11, 131-148. [CrossRef]

54. Yang, W.; Wang, M.; Shi, P. Using MODIS NDVI time series to identify geographic patterns of landslides in vegetated regions. IEEE Geosci. Remote Sens. Lett. 2013, 10, 707-710. [CrossRef]

55. Clerici, A.; Perego, S.; Tellini, C.; Vescovi, P. A procedure for landslide susceptibility zonation by the conditional analysis method. Geomorphology 2002, 48, 349-364. [CrossRef]

56. Wu, Y.; Li, W.; Wang, Q.; Liu, Q.; Yang, D.; Xing, M.; Pei, Y.; Yan, S. Landslide susceptibility assessment using frequency ratio, statistical index and certainty factor models for the Gangu County, China. Arab. J. Geosci. 2016, 9, 84. [CrossRef]

57. O'Brien, R.M. A caution regarding rules of thumb for variance inflation factors. Qual. Quant. 2007, 41, 673-690. [CrossRef]

58. Nasir, I.M.; Khan, M.A.; Yasmin, M.; Shah, J.H.; Gabryel, M.; Scherer, R.; Damaševičius, R. Pearson correlation-based feature selection for document classification using balanced training. Sensors 2020, 20, 6793. [CrossRef]

59. Dormann, C.F.; Elith, J.; Bacher, S.; Buchmann, C.; Carl, G.; Carré, G.; Marquéz, J.R.G.; Gruber, B.; Lafourcade, B.; Leitão, P.J.; et al Collinearity: A review of methods to deal with it and a simulation study evaluating their performance. Ecography 2013, 36, 27-46. [CrossRef]

60. Ragab, M.G.; Abdulkadir, S.J.; Aziz, N.; Al-Tashi, Q.; Alyousifi, Y.; Alhussian, H.; Alqushaibi, A. A novel one-dimensional cnn with exponential adaptive gradients for air pollution index prediction. Sustainability 2020, 12, 10090. [CrossRef]

61. Huang, S.; Tang, J.; Dai, J.; Wang, Y. Signal status recognition based on 1DCNN and its feature extraction mechanism analysis. Sensors 2019, 19, 2018. [CrossRef]

62. Rohrmanstorfer, S.; Komarov, M.; Mödritscher, F. Image Classification for the Automatic Feature Extraction in Human Worn Fashion Data. Mathematics 2021, 9, 624. [CrossRef]

63. Matsugu, M.; Mori, K.; Mitari, Y.; Kaneda, Y. Subject independent facial expression recognition with robust face detection using a convolutional neural network. Neural Netw. 2003, 16, 555-559. [CrossRef]

64. Simard, P.Y.; Steinkraus, D.; Platt, J.C. Best practices for convolutional neural networks applied to visual document analysis. In Proceedings of the International Conference on Document Analysis and Recognition, Edinburgh, UK, 3-6 August 2003. [CrossRef]

65. Cecotti, H. A time-frequency convolutional neural network for the offline classification of steady-state visual evoked potential responses. Pattern Recognit. Lett. 2011, 32, 1145-1153. [CrossRef]

66. Rohit, S.; Chakravarthy, S. A convolutional neural network model of the neural responses of inferotemporal cortex to complex visual objects. BMC Neurosci. 2011, 12, P35. [CrossRef]

67. Lee, S.; Baek, W.K.; Jung, H.S.; Lee, S. Susceptibility mapping on urban landslides using deep learning approaches in mt. Umyeon. Appl. Sci. 2020, 10, 8189. [CrossRef]

68. Pomerat, J.; Segev, A.; Datta, R. On Neural Network Activation Functions and Optimizers in Relation to Polynomial Regression. In Proceedings of the IEEE 2019 IEEE International Conference on Big Data, Los Angeles, CA, USA, 9-12 December 2019; pp. 6183-6185. [CrossRef]

69. Cireşan, D.; Meier, U.; Masci, J.; Schmidhuber, J. Multi-column deep neural network for traffic sign classification. Neural Netw. 2012, 32, 333-338. [CrossRef] [PubMed]

70. Yu, D.; Deng, L.; Seide, F. The deep tensor neural network with applications to large vocabulary speech recognition. IEEE Trans. Audio Speech Lang. Process 2013, 21, 388-396. [CrossRef]

71. Kang, T.G.; Kwon, K.; Shin, J.W.; Kim, N.S. NMF-based target source separation using deep neural network. IEEE Signal Process. Lett. 2015, 22, 229-233. [CrossRef]

72. Sharma, D.; Gupta, N.; Chattopadhyay, C.; Mehta, S. A novel feature transform framework using deep neural network for multimodal floor plan retrieval. Int. J. Doc. Anal. Recognit. 2019, 22, 417-429. [CrossRef]

73. Abdulkadir, S.J.; Alhussian, H.; Nazmi, M.; Elsheikh, A.A. Long short term memory recurrent network for standard and Poor's 500 index modelling. Int. J. Eng. Technol. 2018, 7, 25-29. [CrossRef]

74. Portegys, T.E. A maze learning comparison of Elman, long short-term memory, and Mona neural networks. Neural Netw. 2010, 23, 306-313. [CrossRef]

75. Wöllmer, M.; Schuller, B.; Eyben, F.; Rigoll, G. Combining long short-term memory and dynamic bayesian networks for incremental emotion-sensitive artificial listening. IEEE J. Sel. Top. Signal Process 2010, 4, 867-881. [CrossRef] 
76. Rivest, F.; Kalaska, J.F.; Bengio, Y. Conditioning and time representation in long short-term memory networks. Biol. Cybern. 2014, 108, 23-48. [CrossRef] [PubMed]

77. Lecun, Y.; Bengio, Y.; Hinton, G. Deep learning. Nature 2015, 521, 436-444. [CrossRef]

78. Mou, L.; Ghamisi, P.; Zhu, X.X. Deep recurrent neural networks for hyperspectral image classification. IEEE Trans. Geosci. Remote Sens. 2017, 55, 3639-3655. [CrossRef]

79. Matrenin, P.V.; Manusov, V.Z.; Khalyasmaa, A.I.; Antonenkov, D.V.; Eroshenko, S.A.; Butusov, D.N. Improving accuracy and generalization performance of small-size recurrent neural networks applied to short-term load forecasting. Mathematics 2020, 8, 2169. [CrossRef]

80. Chang, L.C.; Chang, F.J.; Chiang, Y.M. A two-step-ahead recurrent neural network for stream-flow forecasting. Hydrol. Process. 2004, 18, 81-92. [CrossRef]

81. Babalyan, K.; Sultanov, R.; Generozov, E.; Sharova, E.; Kostryukova, E.; Larin, A.; Kanygina, A.; Govorun, V.; Arapidi, G Logloss-Beraf: An ensemble-based machine learning model for constructing highly accurate diagnostic sets of methylation sites accounting for heterogeneity in prostate cancer. PLoS ONE 2018, 13, e0204371. [CrossRef]

82. Jebur, M.N.; Pradhan, B.; Tehrany, M.S. Optimization of landslide conditioning factors using very high-resolution airborne laser scanning (LiDAR) data at catchment scale. Remote Sens. Environ. 2014, 152, 150-165. [CrossRef]

83. Gholami, M.; Ghachkanlu, E.N.; Khosravi, K.; Pirasteh, S. Landslide prediction capability by comparison of frequency ratio, fuzzy gamma and landslide index method. J. Earth Syst. Sci. 2019, 128, 42. [CrossRef]

84. Leir, M.; Michell, A.; Ramsay, S. Regional landslide hazard susceptibility mapping for pipelines in British Columbia. In Proceedings of the 57th Canadian Geotechnical Conference and 5th Joint CGS-IAH Conference: Geo-Engineering for the Society and Its Environment, Old Quebec, QC, Canada, 24-27 October 2004; pp. 19-27.

85. Yin, Y.P.; Wang, W.P.; Zhang, N.; Yan, J.K.; Wei, Y.J. The June 2017 Maoxian landslide: Geological disaster in an earthquake area after the Wenchuan Ms 8.0 earthquake. Sci. China Technol. Sci. 2017, 60, 1762-1766. [CrossRef]

86. Kasim, N.; Taib, K.A.; Mukhlisin, M.; Kasa, A. Triggering Mechanism and Characteristic of Debris Flow in Peninsular Malaysia. Am. J. Eng. Res. 2016, 5, 112-119. 